\title{
11. Prophylaxe und Therapie der akuten septischen Kardiomyopathie
}

K. Werdan

Die Herzinsuffizienz bei Sepsis/septischem Schock und Multiorganversagen - im folgenden als „akute septische Kardiomyopathie“ [57] bezeichnet - bietet im Vergleich zu nichtseptischen Formen der Herzinsuffizienz einige Besonderheiten mit differentialtherapeutischen Konsequenzen [22a]. Die Therapie der eingeschränkten Herzfunktion darf nicht isoliert betrachtet werden: sie muß sich in ein Gesamtkonzept einordnen, das die zusätzlichen Störungen im Bereich der Makro- und Mikrozirkulation sowie auf Organebene mitberücksichtigt (vgl. Kap. 3). Sie ist derzeit noch überwiegend symptomatisch; mit zunehmendem Verständnis der Ursachen der akuten septischen Kardiomyopathie zeichnen sich jedoch bereits auch Ansätze einer kausaleren Behandlungsweise ab. Obwohl nicht nur die systolische, sondern auch die diastolische Herzfunktion in der Sepsis beeinträchtigt ist (vgl. Kap. 2), konzentriert sich derzeit unser Interesse noch weitgehend auf die Besserung der systolischen Funktionsstörung; eine Funktionseinschränkung des rechten Ventrikels infolge pulmonaler Hypertonie bei ARDS und bestehende kardiale Vorerkrankungen erforden zusätzliche differentialtherapeutische Überlegungen. Unsere Behandlungskonzepte wurden überwiegend bei Patienten mit primär septischem Krankheitsbild und Multiorganversagen erarbeitet. Über die Mechanismen der Herzinsuffizienz bei primär nichtseptischem Multiorganversagen - z. B. nach schwerem Trauma - ist dagegen sehr viel weniger bekannt.

Die Prophylaxe der akuten septischen Kardiomyopathie beschränkt sich derzeit noch auf allgemeine Sepsisprophylaxemaßnahmen.

\section{Besonderheiten der Herzinsuffizienz bei Sepsis/septischem Schock und Multiorganversagen: akute septische Kardiomyopathie}

Die Kasuistik der Abb. 11.1 verdeutlicht die typischen Herz-Kreislauf-Veränderungen, wie sie bei gramnegativem und grampositivem septischen Schock im Rahmen des Multiorganversagens gefunden werden: Der Blutdruckabfall infolge der Erniedrigung des systemischen Gefäßwiderstands bis auf etwa 30\% der Norm kann bis zu einem gewissen Grad durch einen Anstieg des Herzzeitvolumens kompensiert werden. Herzzeitvolumen/Herzindex und Schlagvolumenin- 


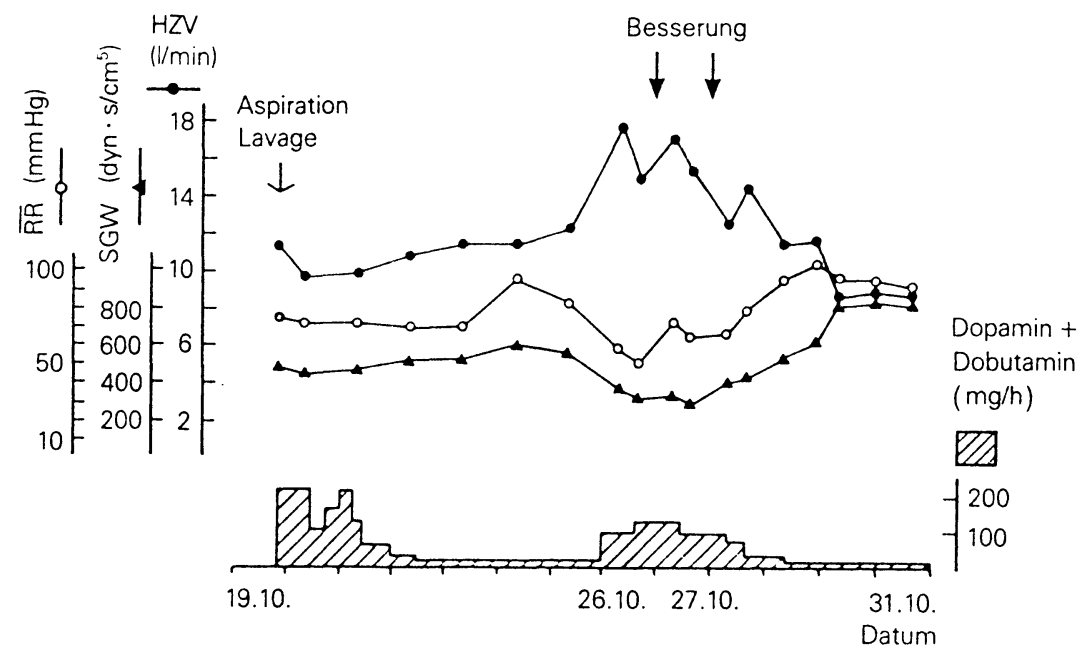

Abb. 11.1. Kasuistik: Herz-Kreislauf-Befunde bei einem 47jährigen Patienten mit Pseudomonassepsis nach Aspirationspneumonie. Aspiratonspneumonie am 19.10. Nach initialer Befundbesserung kommt es bis 26.10. zu einer Befundverschlechterung mit katecholaminpflichtiger Schocksymptomatik. Ab 27.10. tritt eine anhaltende klinische Besserung ein. (Aus Werdan et al. [57])

dex steigen dabei um so mehr an, je stärker der systemische Gefäßwiderstand abfällt (Abb. 11.2). Fehlt eine relevante kardiale Vorschädigung, so liegen die gemessenen Herzfunktionsparameter dabei auch beträchtlich höher als die gesunder Probanden mit einem „normalen“ systemischen Gefäßwiderstand um $1100 \mathrm{dyn} \cdot \mathrm{cm}^{-5} \cdot \mathrm{s}$ (Abb. 11.2).

Eine so weitgehende Kompensation - d.h. ein Anstieg des Herzzeitvolumens auf das Zwei- bis Dreifache der Norm - wird allerdings im septischen Schock nur selten beobachtet, v. a. nicht bei protrahierten Verläufen: die Pumpfunktionsparameter des Herzens sind dabei zwar im Vergleich zu gesunden Probanden mit "normalem“ systemischen Gefäßwiderstand meist nicht erniedrigt oder sogar leicht erhöht; berücksichtigt man jedoch die inverse Korrelation mit dem systemischen Gefäßwiderstand (Abb. 11.2; Kap. 2: Abb. 2.5), so wird die eingeschränkte Pumpleistung des Herzens bei vielen Patienten bereits in der hyperdynamen Phase des septischen Schocks [12, 31, 44] und sogar bereits bei septischen Patienten mit noch normalem Blutdruck $[31,35]$ rasch evident, sowohl bei verschiedenen Formen der gramnegativen, der grampositiven und auch der Pilzsepsis (Abb. 11.3). Bezieht man weiterhin auch noch die in der Sepsis vorhandene $\mathrm{O}_{2}$-Verwertungsstörung im Gewebe mit verminderter $\mathrm{O}_{2}$-Extraktion (Kap. 10) und erhöhtem Skelettmuskel- $\mathrm{O}_{2}$-Partial druck (Abb. 11.4) in die Überlegungen mit ein, so wird klar, daß die Behandlung der akuten Herzinsuffizienz in der Sepsis eine eigenständige Betrachtungsweise erfordert, die sich nicht ausschließlich an der Behandlung der nichtseptisch bedingten akuten Herzinsuffizienz orientieren kann. 


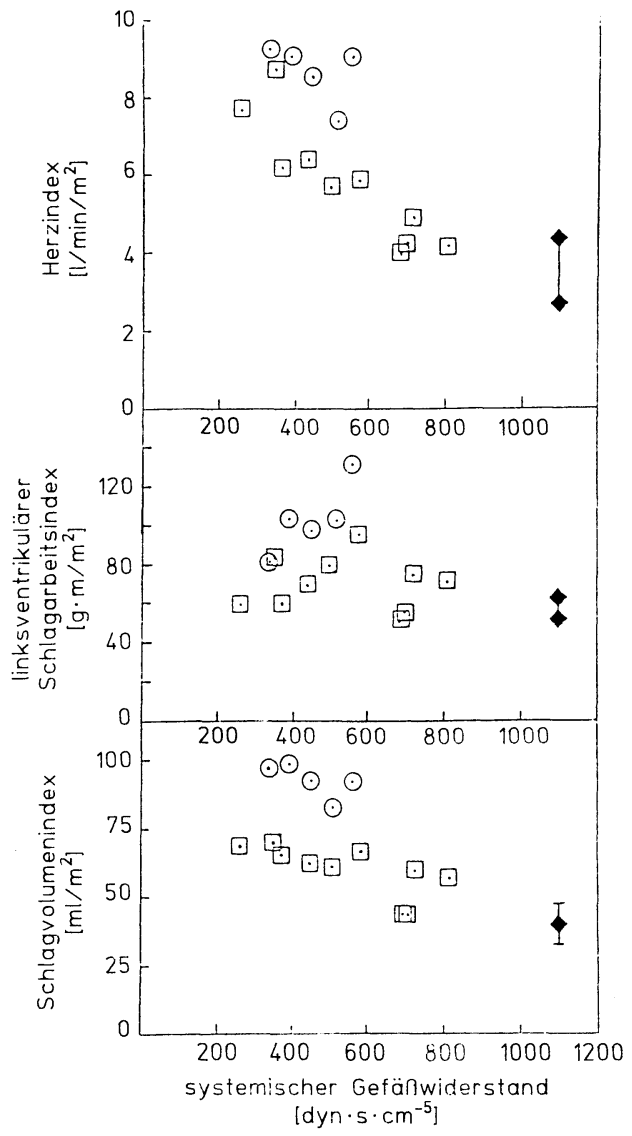

Abb. 11.2. Herzfunktionsparameter von 2 Patienten mit septischem Schock $(\mathrm{O}, \square)$ in Abhängigkeit vom systemischen Gefäßwiderstand. Bei diesen beiden Patienten wurden während der Krankheitsverläufe mit klinischer Befundbesserung in einem Zeitraum von 20 Tagen (Patient 1, O) bzw. von 8 Tagen (Patient 2, $\square$ ) mehrfach Herzfunktionsparameter mittels SwanGanz-Katheter ermittelt: Herzindex, linksventrikulärer Schlagarbeitsindex, Schlagvolumenindex. Die Werte wurden in Abhängigkeit von dem jeweils aktuellen systemischen Gefäßwiderstand aufgetragen. Zum Vergleich sind die Normalwerte Gesunder ( $\bullet$; aus [24], S. 367) aufgeführt

Bei jedem Patienten mit drohender oder manifester Sepsis bzw. mit drohendem oder manifestem Multiorganversagen sollte die akute septische Kardiomyopathie in dreierlei Weise zum frühestmöglichen Zeitpunkt charakterisiert werden:

a) Schweregrad der akuten septischen Kardiomyopathie: dies gelingt durch Beurteilung der Herzfunktionsparameter in Abhängigkeit vom systemischen Gefäßwiderstand (Abb. 11.2) mittels Swan-Ganz-Katheter; echokardiographisch (transthorakal [12], transösophageal [5,9]) wird der Schweregrad dagegen bei Nichtbeachtung der erniedrigten Nachlast (vgl. Abb. 11.2) häufig unterschätzt [13]. Zur Beurteilung der rechtsventrikulären Dysfunktion s. Abschn. „spezielle Aspekte bei der Behandlung der rechtsventrikulären Dysfunktion bei akuter septischer Kardiomypathie“, S. 241-242. Weitere nichtinvasive Verfahren zur Beurteilung der Herzfunktion sind die Impedanzkardiographie [55] sowie die Bestimmung der systolischen und diastolischen Zeitintervalle. Ihre Aussagekraft ist sehr eingeschränkt. Dagegen hat die Radionuklidventrikulographie wesentliches zur Charakterisierung der Herzschädigung in der Sepsis beigetragen [22a, 26]. 


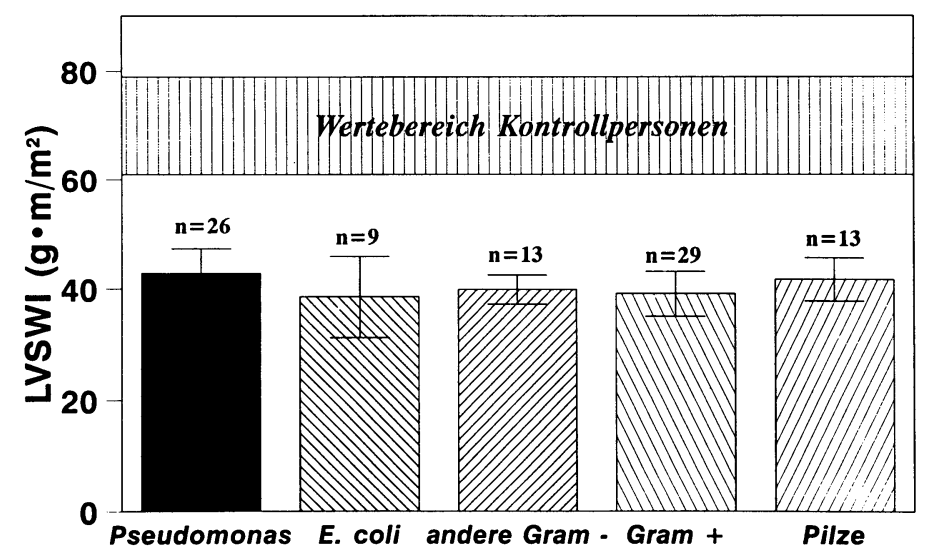

Abb. 11.3. Kardiale Dysfunktion - gemessen als linksventrikulärer Schlagarbeitsindex (LVSWI) - bei verschiedenen Formen der gramnegativen (Gram -), der grampositiven $($ Gram +$)$ und der Pilz-Sepsis. (Modifiziert nach [31])

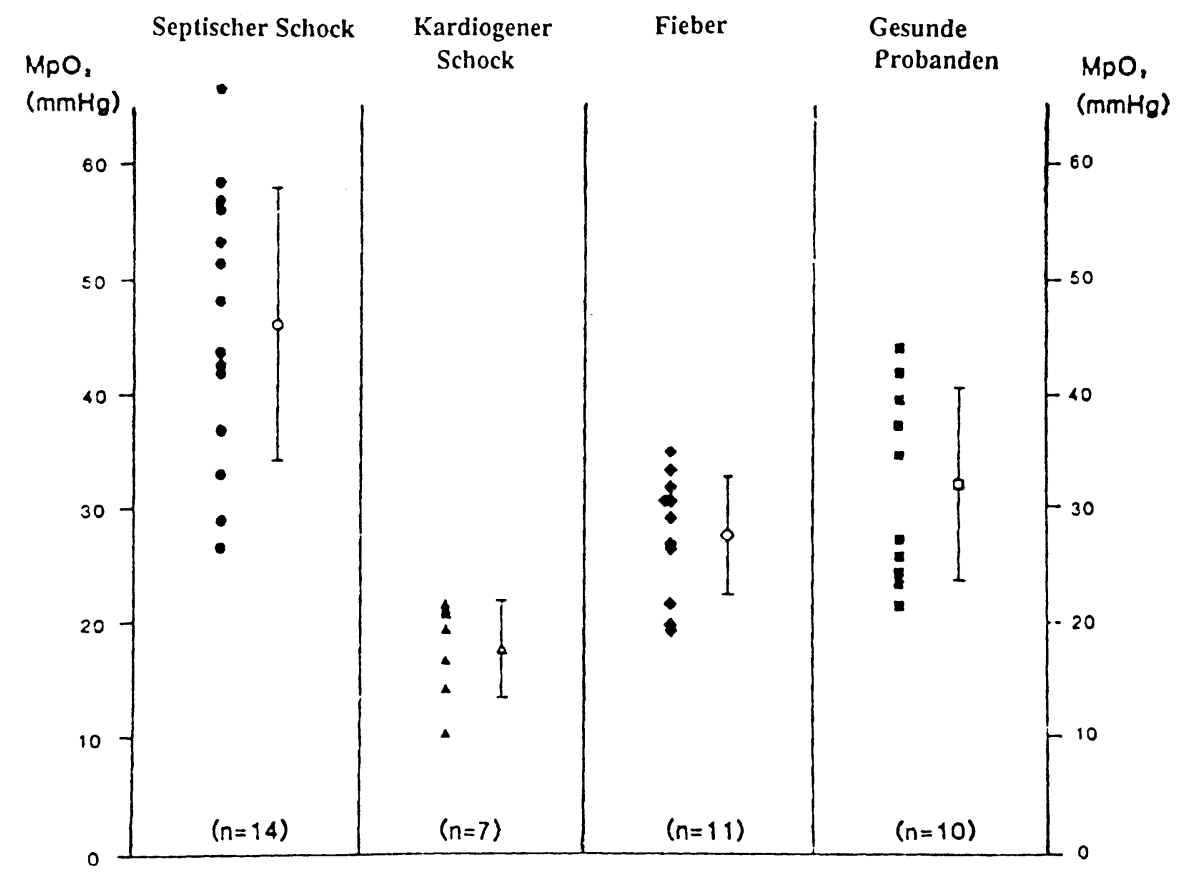

Abb. 11.4. Skelettmuskel(Musculus-biceps-brachii)- $\mathrm{O}_{2}$-Partialdruckmessungen bei Patienten mit Sepsis, kardialem Pumpversagen, Fieber und bei gesunden Probanden. (Aus Werdan et al. [57]) 
b) Funktionelle Relevanz der akuten septischen Kardiomyopathie: diese ist um so bedeutungsvoller, je ausgeprägter die Organperfusion und damit die Organfunktion in der Sepsis und im Multiorganversagen bereits beeinträchtigt ist: SIRS/Sepsis - sepsisinduzierte Hypotonie/MODS/schwere Sepsis - septischer Schock - refraktärer septischer Schock (zur Terminologie s. unten);

c) Vorliegen kardialer Begleiterkrankungen: sie können sich zusätzlich auf die Herzfunktion ungünstig auswirken (s. S. 242).

\section{Terminologie}

Mit Ausnahme der letzten beiden Begriffe: in Anlehnung an The ACCP/SCCM Consensus Conference Committee (1992) Definitions for sepsis and organ failure and guidelines for the use of innovative therapies in sepsis. Chest 101: 1644-1655.

\section{Infektion}

Entzündliche Gewebereaktion auf Mikroorganismen oder Invasion von Mikroorganismen in normalerweise steriles Gewebe.

\section{Bakteriämie}

Vorhandensein vitaler Bakterien im Blut.

SIRS („systemic inflammatory response syndrome")

Systemisch-entzündliche Reaktion auf verschiedene schwere klinische Insulte, charakterisiert durch 2 oder mehr der folgenden Symptome:

1) Körpertemperatur $>38^{\circ} \mathrm{C}$ oder $<36^{\circ} \mathrm{C}$,

2) Herzfrequenz $>90 / \mathrm{min}$,

3) Atemfrequenz $>20 / \mathrm{min}$ oder $\mathrm{p}_{\mathrm{a}} \mathrm{CO}_{2}<32 \mathrm{mmHg}$,

4) Leukozyten $>12000 / \mathrm{mm}^{3}$ oder $<4000 / \mathrm{mm}^{3}$, oder $>10 \%$ unreife (stabförmige) Formen.

Sepsis

Systemische Reaktion auf eine Infektion, charakterisiert durch 2 oder mehr der folgenden, durch die Infektion hervorgerufenen Symptome:

1) Körpertemperatur $>38^{\circ} \mathrm{C}$ oder $<36^{\circ} \mathrm{C}$,

2) Herzfrequenz $>90 / \mathrm{min}$,

3) Atemfrequenz $>20 / \mathrm{min}$ oder $\mathrm{p}_{\mathrm{a}} \mathrm{CO}_{2}<32 \mathrm{~mm} \mathrm{Hg}$,

4) Leukozyten $>12000 / \mathrm{mm}^{3}$ oder $<4000 / \mathrm{mm}^{3}$, oder $>10 \%$ unreife (stabförmige) Formen.

Schwere Sepsis

Sepsis, assoziiert mit Organdysfunktion, Minderperfusion oder Hypotonie. Minderdurchblutung und Durchblutungsstörungen können beinhalten, sind aber nicht beschränkt auf: Laktatazidose, Oligurie oder eine akute Änderung der Bewußtseinslage.

MODS („multiple organ dysfunction syndrome")

Vorhandensein einer dermaßen geänderten Organfunktion bei Akutkranken, daß die Homöostase ohne Intervention nicht mehr aufrechterhalten werden kann. 
Sepsisinduzierte Hypotonie

Systolischer Blutdruck $<90 \mathrm{mmHg}$ oder Reduktion um $\geq 40 \mathrm{mmHg}$ des Ausgangswerts bei Fehlen anderer Hypotonieursachen.

\section{Septischer Schock}

Sepsisinduzierter Schock mit Hypotonie trotz adäquater Volumensubstitution, einhergehend mit Durchblutungsstörungen; letztere können beinhalten, sind aber nicht beschränkt auf: Laktatazidose, Oligurie oder eine akute Änderung der Bewußtseinslage. Die Behandlung mit inotropen oder vasokonstriktorischen Substanzen kann zur Maskierung der Hypotonie zum Zeitpunkt der Feststellung von Durchblutungsstörungen führen.

\section{Refraktarer septischer Schock}

Septischer Schock ohne rasches Ansprechen auf Volumengabe (z. B. $500 \mathrm{ml} \mathrm{NaCl}$ in $30 \mathrm{~min}$ ) und Vasopressoren (z. B. Dopamin $>10 \mu \mathrm{g} / \mathrm{kgKG} / \mathrm{min}$ ).

\section{Akute septische Kardiomyopathie}

Myokardschädigung im Rahmen einer Sepsis mit der Folge einer im Verhältnis zum systemischen Gefäßwiderstand verminderten Pumpfunktion des Herzens.

\section{Behandlungsziele bei akuter septischer Kardiomyopathie}

Je ausgeprägter die Myokarddepression und die Vasodilatation eines Patienten mit septischem Schock, umso größer ist die Gefahr des Versterbens [54]. Die Normalisierung der Herz- und Kreislauffunktion erscheint demzufolge als Therapieziel sinnvoll. Diese - derzeit noch weitgehend symptomatische - Behandlung beinhaltet zunächst die rasche und adäquate Volumensubstitution, gegebenenfalls gefolgt und unterstützt durch den Einsatz von Katecholaminen (s. S. 209-233).

Die im folgenden aufgeführten Therapiezielkriterien sind lediglich als Orientierungsvorschläge anzusehen; sie werden durchaus kontrovers diskutiert und sind größtenteils auch nicht ausreichend validiert. Anstelle der komplexen pathophysiologischen Definition des septischen Schocks wird als praktikabler Parameter zur Therapieentscheidung die Höhe des arteriellen Blutdrucks herangezogen: Zur Sicherung einer ausreichenden Koronar- und Zerebralperfusion sollte der arterielle Mitteldruck 60-70 mm Hg und der systolische Blutdruck $90 \mathrm{~mm} \mathrm{Hg} \mathrm{nicht}$ unterschreiten $[26,38]$.

Diesem häufig praktizierten Vorgehen stehen Vorschläge gegenüber, die sich mehr an therapeutischen Zielparametern (s. S. 206-209) orientieren: an der Sicherung einer ausreichenden Organdurchblutung und $\mathrm{O}_{2}$-Versorgung sowie der Verringerung des Schweregrads von septisch bedingter Gefäßschädigung und Kardiomyopathie. Entsprechende Richtwertvorschläge sind in Tabelle 11.1 aufgeführt. Inwieweit dadurch eine Prognoseverbesserung zu erzielen ist, bleibt Gegenstand der Diskussion (s. dazu auch Abschn. „Katecholamine und supranormales $\mathrm{O}_{2}$-Angebot - mit mehr Sauerstoff allein ist es nicht getan“, S. 223).

Voraussetzung für eine wirksame Therapie ist eine möglichst frühzeitige Diagnose und Schweregradeinschätzung der septischen Herz-Kreislauf-Insuffi- 
zienz; intraarterielle Druckregistrierung und ein Pulmonaliskatheter mit Thermodilutionsmessung erlauben die Messung und Berechnung aller zur Überwachung solcher kritisch Kranker notwendigen hämodynamischen Daten; nach Parrillo [26] sollten alle Patienten mit der Verdachtsdiagnose eines septischen Schocks mit diesem hämodynamischen Monitoring überwacht werden; die gleiche Empfehlung findet sich für Patienten mit septischem Schock bei Niemer et al. ([24], S. 1592), und sie wird auch für kritisch Kranke mit Sepsis von den zuständigen amerikanischen Ärztevereinigungen (Zitat 17 in [56]) gegeben. Zur Beurteilung - des Blutdrucks sind der arterielle Mitteldruck (s. Übersicht unten und Tabelle 11.1) in der Regel auch der systolische Blutdruck (vgl. „Terminologie“ S. 204-205) geeignet; allerdings kann bereits bei Vorliegen eines niedrigen diastolischen Drucks trotz eines systolischen Blutdrucks von 90 mm Hg eine Organminderperfusion vorliegen [22a, 26].

\section{Zielkriterien bei der Behandlung der akuten septischen Kardiomyopathie und des septischen Schocks}

\section{Blutdruck}

- Mittlerer arterieller Blutdruck $\geq 60-70 \mathrm{~mm} \mathrm{Hg}$.

\section{Organdurchblutung}

- Die Durchblutung - z.B. von Nieren, Leber, ZNS und Lungen - wird als adäquat angesehen, wenn die Organfunktion nicht eingeschränkt ist. Eine Urinausscheidung von $>20 \mathrm{ml} / \mathrm{h}$ zeigt indirekt eine ausreichende Nierendurchblutung an [26].

- Verhinderung eines Anstiegs des Blutlaktats.

- Parameter des $\mathrm{O}_{2}$-Stoffwechsels und der Gewebeoxygenierung: s. Kap. 10.

Quantifizierung des Schweregrads der septisch bedingten Gefäßschädigung mit Vasodialatation

- Systemischer Gefäßwiderstand: Abweichung vom Sollwert $\left(1100 \pm 200 \mathrm{dyn} \cdot \mathrm{cm}^{-5} \cdot \mathrm{s}\right.$; s. Abb. 11.1).

Quantifizierung des Schweregrads der akuten septischen Kardiomyopathie

- Sollwertabweichungen von Pumpfunktionsparametern (z. B. Herzeitvolumen/ Herzindex, Schlagvolumenindex, rechts- und linksventrikulärer Schlagarbeitsindex; rechts- und linksventrikuläre Auswurffraktion), betrachtet in Relation zum aktuellen systemischen Gefäßwiderstand (s. Abb. 2.5, 11.2; s. dazu auch Tabelle 11.1).

Die Vasodilatation läßt sich an der Erniedrigung des systemischen Gefäßwiderstands und die akute septische Kardiomyopathie an der - in Relation zum systemischen Gefäßwiderstand - verminderten Herzfunktion (z. B. Herzindex, Schlagvolumenindex, linksventrikulärer Schlagarbeitsindex; Abb. 2.5, Abb. 11.2) erkennen. Das klinische Erscheinungsbild des septischen Schocks stellt bereits ein weit forgeschrittenes Krankheitsstadium dar! Der septische Schock ist in der Regel hyperdynam (Herzindex $>5,51 / \mathrm{min} \cdot \mathrm{m}^{2}$; systemischer Gefäßwiderstand 
Tabelle 11.1. Richtwerte hämodynamischer Parameter bei Patienten mit drohender oder manifester Sepsis und Multiorganversagen. (Aus Conrad et al. [4])

\begin{tabular}{lcll}
\hline Parameter & $\begin{array}{l}\text { Normal- } \\
\text { wert }\end{array}$ & $\begin{array}{l}\text { Richt- } \\
\text { wert }\end{array}$ & Einheit \\
\hline Herzfrequenz & $70-90$ & $<120$ & $\mathrm{~min}^{-1}$ \\
Mittlerer arterieller Blutdruck & $80-100$ & $>70$ & $\mathrm{~mm} \mathrm{Hg}$ \\
Mittlerer Pulmonalarteriendruck & $12-16$ & $<20$ & $\mathrm{~mm} \mathrm{Hg}$ \\
Pulmonalkapillardruck & $8-12$ & $12-16$ & $\mathrm{~mm} \mathrm{Hg}$ \\
Rechtsatrialer Druck & $5-8$ & $>8$ & $\mathrm{~mm} \mathrm{Hg}$ \\
Herzindex & $3,5-4,5$ & $>4,5$ & $1 \cdot \mathrm{min} \cdot \mathrm{m}^{-2}$ \\
Schlagvolumenindex & $35-45$ & $>45$ & $\mathrm{ml} \cdot \mathrm{m}^{-2}$ \\
Linksventrikulärer Schlagarbeitsindex & $45-65$ & $>45$ & $\mathrm{~g} \cdot \mathrm{m} \cdot \mathrm{m}^{-2}$ \\
Rechtsventrikulärer Schlagarbeitsindex & $4-8$ & $>10$ & $\mathrm{~g} \cdot \mathrm{m} \cdot \mathrm{m}^{-2}$ \\
Systemischer Gefäßwiderstand & $1050-1400$ & $700-1200$ & $\mathrm{dyn} \cdot \mathrm{s} \cdot \mathrm{cm}^{-5}$ \\
Pulmonaler Gefäßwiderstand & $30-120$ & $<150$ & $\mathrm{dyn} \cdot \mathrm{s}^{\mathrm{a}} \cdot \mathrm{cm}^{-5}$ \\
Arterieller $\mathrm{O}_{2}$-Partialdruck & $90-95$ & $>60$ & $\mathrm{~mm} \mathrm{Hg}$ \\
Arterielle $\mathrm{O}_{2}$-Sattigung & $95-100$ & $>90$ & $\%$ \\
Gemischtvenöser $\mathrm{O}_{2}$-Partialdruck & $35-50$ & $>35$ & $\mathrm{~mm} \mathrm{Hg}$ \\
Gemischtvenöse $\mathrm{O}_{2}$-Sättigung & $70-75$ & $>60$ & $\%$ \\
$\mathrm{O}_{2}$-Angebot & $550-650$ & $>650$ & $\mathrm{ml} \cdot \mathrm{min}^{-1} \cdot \mathrm{m}^{-2}$ \\
$\mathrm{O}_{2}$-Verbrauch & $110-150$ & $>170$ & $\mathrm{ml} \cdot \mathrm{min}^{-1} \cdot \mathrm{m}^{-2}$ \\
$\mathrm{O}_{2}$-Extraktionsverhältnis & $25-30$ & $<30$ & $\%$ \\
Pulmonale Shuntfraktion & $3-5$ & $<5$ & $\%$ \\
\hline
\end{tabular}

a Angaben in [4] als Index; die Umrechnung erfolgte unter Zugrundelegung einer Körperoberfläche von $1.7 \mathrm{~m}^{2}$.

$\left.\leq 600 \mathrm{dyn} \cdot \mathrm{s} \cdot \mathrm{cm}^{-5}\right)$ und nur in der Spätphase oder bei nicht ausreichender Volumensbsutitution hypodynam $(<2,5 ; \geq 1200$; Klassifikation nach [24], S. 1553 und 1581-1584).

Eine Einschränkung der links- und rechtsventrikulären Pumpfunktion findet sich nicht erst im septischen Schock, sondern bereits bei normotensiven Sepsispatienten [31,35]. Die Therapie dieser akuten septischen Kardiomyopathie beginnt somit nicht erst im manifesten septischen Schock, sondern spätesten bei der sepsisbedingten Hypotonie oder - trotz normalen Blutdrucks - bei Vorliegen einer Organminderperfusion! Je schneller die Diagnose gestellt wird und je rascher und konsequenter die kurativen Therapiemaßnahmen eingeleitet werden, desto besser ist die Prognose dieser Patienten ([24], S. 1585).

Die akute septische Kardiomyopathie ist vorwiegend durch eine primär myokardiale systolische und diastolische Funktionsstörung des linken und rechten Ventrikels charakterisiert (s. Kap. 2), während eine verminderte $\mathrm{O}_{2}$-Versorgung des Herzens infolge von Koronarstenosen nur bei Patienten mit zusätzlich bestehender koronarer Herzkrankheit oder bei Hypotonie zu erwarten ist. Eine pulmonale Hypertonie im Rahmen eines ARDS kann darüber hinaus zu einer 
zusätzlichen Belastung des rechten Ventrikels führen, verbunden mit einer mechanischen Beeinträchtigung des linken Ventrikels durch ein Kammerseptumshift nach links.

Aus dem Gesagten wird ersichtlich, daß neben der Besserung einer pulmonalen Hypertonie bei ARDS (s. S. 241-242) s. auch Kap. 12; v. a. die Besserung der systolischen und diatolischen Funktionsstörung des linken Ventrikels therapeutische Zielkriterien sind, um letztendlich die Organperfusion in der Sepsis zu optimieren. Hierfür stehen - nach Ausschöpfung der gesicherten Kausaltherapie mit radikaler Herdsanierung und adäquater Antibiotikatherapie - symptomatische Maßnahmen und weitere kausale, in ihrer kausale, in ihrer Wirkasmkeit aber noch wenig bis nicht gesicherte Behandlungsversuche zur Verfügung.

\section{Kontrollierte Therapic der akuten septischen Kardiomyopathie und des septischen Schocks}

I. Bestätigung der korrekten Diagnose

A) Differentialdiagnose des Schocks: Rechtsherzkatheterisierung

B) Intraarterielle Druckmessung: Ungenauigkeit der Blutdruckmessung mit Manschette im Schock

C) Quantifizierung von Schweregrad und funktioneller Relevanz der akuten septischen Kardiomyopathie (s. S. 202-204);

II. Gewährleistung des sofortigen Erkennens und der raschen Behandlung von Blutdruckänderungen

Blutdruckinstabilität im septischen Schock;

III. Elimination von Ursachen, die zur Myokarddepression und Stoffwechselentgleisung führen

A) Korrektur einer Hypoxie,

B) Korrektur einer Azidose,

C) Korrektur von Hypophosphatämie und Hypokalzämie,

D) Korrektur von sonstigen Elektrolytstörungen;

IV. Hämodynamisches Monitoring zur Therapieoptimierung

A) Volumensubstitution: Optimierung der Vorlast (s. S. 209-217, 232):

1) Pulmonalkapillardruck,

2) rechtsatrialer Druck,

3) Cave: Lungenödem,

B) Therapie mit inotropen und vasokonstriktorischen Substanzen (s. S. 217-231):

1) Optimierung des Herzzeitvolumens/Herzindex,

2) nach Erzielen des optimalen Herzzeitvolumens/Herzindex: pharmakologische Blutdrucksteigerung mit Nachlasterhöhung falls erforderlich,

3) Gewährleistung der exakten Infusionsgeschwindigkeit.

C) Optimierung der Organdurchblutung (s. auch Kap. 10)

1) Oligurie: 
a) Maximierung des Herzzeitvolumens mittels Volumensubstitution

b) Dopamin, Noradrenalin, andere Vasokonstriktoren,

c) Vasodilatatoren

2) pulmonale Shunts (s. auch Kap. 12): Cave: Zunahme durch Pharmaka (s. Text),

3) Verminderte Hirndurchblutung: Herz-Kreislaufstabilisierung; Karotisstenosen?

4) Verminderte Leberdurchblutung (s. Kap. 10);

V. Rhythmusmonitoring (s. S. 232)

A) Antiarrhythmika,

B) elektrische Kardioversion;

VI. ${ }^{1}$ Optimierung der Atmung/Beatmung und Reduktion der Herzarbeit (s. S. 232-233)

A) Optimierung der Oxygenierung (Kontrollparameter: $\mathrm{p}_{\mathrm{a}} \mathrm{O}_{2} ; \mathrm{S}_{\mathrm{a}} \mathrm{O}_{2}$ )

B) Erhöhte Atemarbeit durch Atemunterstützung reduzieren (v.a. bei eingeschränktem Herzzeitvolumen),

C) Belastung des Herzens durch PEEP, CMV, IMV bedenken,

D) Anxiolyse, Analgesie, Fiebersenkung [20]

E) Cave: myokarddepressive Medikaton: Anästhetika, Barbiturate, Meperiden, Kombination von Opiaten und Benzodiazepinen;

VII. Fokussanierung, Antibiotika (s. auch Kap. 4)

VIII. ${ }^{1}$ Kausale Therapieansätze (s. S. 233-241)

\section{Symptomatische Therapie der akuten septischen Kardiomyopathie}

Die symptomatische Therapie beinhaltet als erstes die Volumensubstitution und danach die Gabe von positiv inotropen und vasoaktiven Substanzen.

\section{Volumensubstitution}

Die sepsisbedingte Gefäßschädigung - Vasodilation und Leakage - mit Abstrom großer Flüssigkeitsmengen ins Interstitum birgt die Gefahr einer relativen intravasalen Hypovolämie in sich. Eine weitere Verschlechterung der Zirkulation durch Blutdruckabfall und Abnahme des Herzzeitvolumens ist Folge einer absoluten Hypovolämie (Fieber, Erbrechen, Diarrhoe, Volumenverlust durch Drainagen und Sequestrierung, nicht ausreichende orale Flüssigkeitsaufnahme), einer Hypalbuminämie (verminderte hepatische Produktion und vermehrter extravasaler Abstrom) und - bei einigen Patienten mit septischem Schock - einer inadäquaten Polyurie [19]. Frühzeitige Volumenzufuhr ist unbestritten die wich-

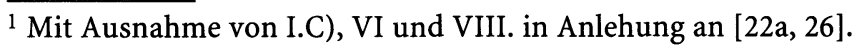


Tabelle 11.2. Pharmakologische Kenndaten künstlicher Kolloidlösungen. DX Dextran, HES Hydroxyethylstärke, KOD kolloidonkotischer Druck. (Aus Sirtl u. Laubenthal [45])

\begin{tabular}{|c|c|c|c|}
\hline & Gelatine & Dextran & HES \\
\hline $\begin{array}{l}\text { Mittlere Molekülmasse } \mathrm{M} \overline{\mathrm{w}}(\mathrm{kD}) \\
\text { (Substitutionsgrad bei HES) }\end{array}$ & $30-35$ & $\begin{array}{l}40 \\
60 \\
70\end{array}$ & $\begin{array}{l}40 / 0,55 \\
200 / 0,5-0,62 \\
450 / 0,7\end{array}$ \\
\hline Konzentration $[\mathrm{g} / \mathrm{dl}]$ oder $[\%]$ & $3-5,5$ & $\begin{array}{r}6(\mathrm{Dx} 60) \\
10(\mathrm{Dx} 40)\end{array}$ & $\begin{array}{l}3 \text { (HES 200) } \\
6(\text { HES } 40 ; 200 ; 450) \\
10 \text { (HES 200) }\end{array}$ \\
\hline $\mathrm{KOD}[\mathrm{hPa}]$ & $35-39$ & $\begin{array}{r}230(\mathrm{Dx} \mathrm{40)} \\
80(\mathrm{Dx} 60)\end{array}$ & $\begin{array}{l}33(6 \%) \\
85(10 \%)\end{array}$ \\
\hline Wasserbindung $[\mathrm{ml} / \mathrm{g}]$ & $42-51$ & $26-29$ & 20 \\
\hline Volumenwirkdauer $[\mathrm{h}]$ & $2-3$ & $\begin{array}{l}2-4(\mathrm{D} \times 40) \\
4-6(\mathrm{D} \times 60)\end{array}$ & $\begin{array}{l}\text { 2-3 (HES 240) } \\
4-6 \text { (HES 200) } \\
6-8(\text { HES } 450)\end{array}$ \\
\hline Verteilungsraum & $\begin{array}{l}\text { intra- und } \\
\text { extravasal }\end{array}$ & intravasal & intravasal \\
\hline Volumenfülleffekt & $0,7-0,8(-1,0)$ & $\begin{array}{l}1,2(\text { Dx 60) } \\
2,0(\text { Dx 40) }\end{array}$ & $\begin{array}{l}0,8 \text { (HES 40) } \\
1,2-1,3\end{array}$ \\
\hline
\end{tabular}

tigste therapeutische Maßnahme, um rasch ein ausreichendes zirkulierendes Blutvolumen und damit einen suffizienten venösen Rückstrom und ein adäquates Herzzeitvolumen zu erzielen. Damit soll die Pumpleistung des Herzens gesteigert (Abb 11.5; [46]), die Gewebeperfusion und -oxygenierung verbessert und eine regelrechte Organfunktion sichergestellt werden (Abb. 11.5; [33, 46]). Die dazu notwendingen, teils beträchtlichen Volumina lassen es dringend ratsam erscheinen, diese Flüssigkeitssubstitution bei Patienten mit septischem Schock unter regelmäßigem hämodynamischen Monitoring mittels Swan-Ganz-Katheter vorzunehmen.

Als Zielkriterien einer adäquaten Flüssigkeitssubstitution dienen die kardialen Füllungsdrücke, Sauerstofftransportparameter und der Hämatokritwert [46]; häufig zeigt auch ein Abfall des erhöhten Blutlaktatspiegels unter Volumensubstitution die Besserung an.

Kardiale Füllungsdrücke: Hier können als Richtwerte - allerdings mit großer individueller Schwankungsbreite [25] ein rechtsatrialer Druck - als Maß der rechtsventrikulären Vorlast - von mindestens $10-12 \mathrm{mmHg}$ und ein Pulmonalkapillardruck - als Maß der linksventrikulären Vorlast - von 12-15 mm Hg [46] bzw. 12-16-18 mm Hg ([24], S. 1585; [26]) dienen, wobei zur Einstellung aufgrund der erhöhten Dehnbarkeit des Herzens in der Sepsis relativ große Flüssigkeitsmengen erforderlich sind. Die gleichzeitige Bestimmung des Herzzeitvolumens bei verschiedenen Füllungsdrücken trägt zur Optimierung dieses 


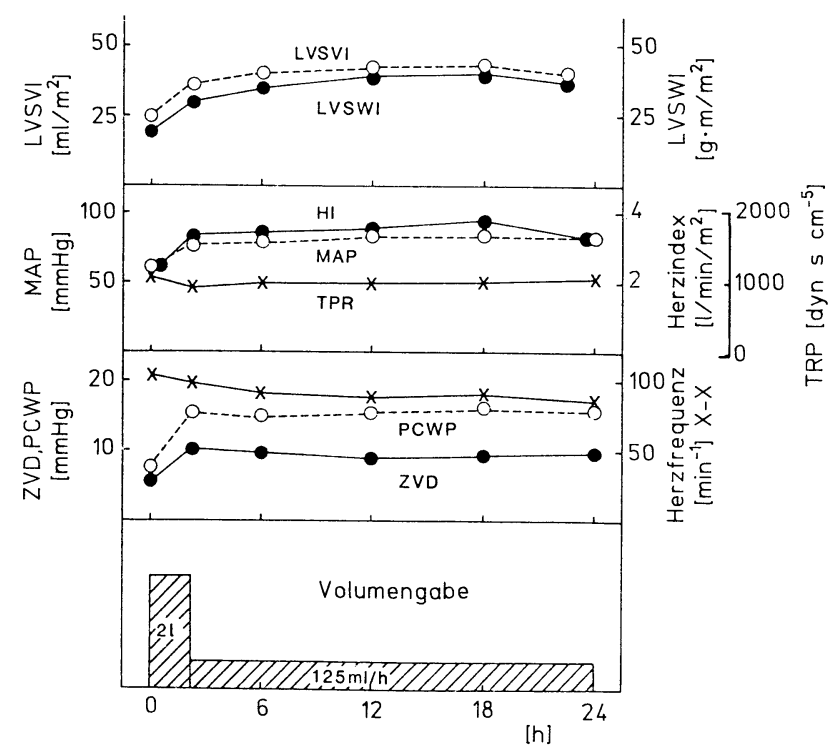

Abb. 11.5. Symptomatische Therapie des septischen Schocks: Volumensubstitution $(n=18)$. Herz-Kreislauf-Veränderungen nach i.v.-Akutinfusion von 21 Flüssigkeit über $2 \mathrm{~h}$, anschließend $125 \mathrm{ml} / \mathrm{h}$ in den folgenden $22 \mathrm{~h}$. ZVD zentraler Venendruck; PCWP Pulmonalkapillardruck; MAP mittlerer arterieller Druck; TPR systemischer Gefäßwiderstand; HI Herzindex; LVSWI inksventrikulärer Schlagarbeitsindex, LVSVI linksventrikulärer Schlagvolumenindex. (Nach Rackow et al. [33])

Vorgehens bei und läßt rechtzeitig eine volumenbedingte Drucküberlastung mit Lungenstauung und Abnahme des Herzzeitvolumens erkennen. Bei einem koronarkranken Septiker mit einem „starren“ ischämischen Ventrikel ist allerdings bei der Volumensubstitution Vorsicht geboten ([34]; [37], S. 108-123).

Dieser eher großzügigen Flüssigkeitsgabe stehen manche Therapeuten - nicht jedoch der Autor - eher zurückhaltend gegenüber, aus Sorge vor peripherer und pulmonaler Ödembildung mit Einschränkung der Gewebeoxygenierung und der Gefahr der Zunahme pulmonaler Shunts: sie substituieren einen vorbestehenden Volumenmangel nur bis zum Erreichen normaler oder allenfalls nur gering erhöhter Füllungsdrücke und setzen anschließend vasokonstriktorische Katecholamine ein ([27], S. 89-93).

Der Wert der kardialen Füllungsdrücke als Zielkriterien der Volumensubstitution wird durch einige Faktoren eingeschränkt ([13]; ausführliche Diskussion und Literaturangaben in [46]): so kann eine sich ausbildende pulmonale Hypertonie die Nachlast des rechten Ventrikels verändern; darüber hinaus ist die septische Kardiomyopathie durch eine Einschränkung der Myokardkontraktilität beider Ventrikel charakterisiert, mit Dilalation, verminderter Auswurffraktion und einer geänderten Druck-Volumen-Relation. Die kardialen Füllungsdrücke korrelieren demzufolge nicht zwangsläufig mit den Ventrikelvolumina, und nicht 
selten bleibt ein Ansteig des Schlagvolumens trotz ausreichender Flüssigkeitsgabe aus. Vor allem Patienten mit einer ausgeprägten Vergrößerung des rechten Ventrikels scheinen hämodynamisch weniger von einer Volumensubstitution zu profitieren als erwartet: bei diesen Patienten steigt zwar der Pulmonalkapillardruck deutlich an, das enddiastolische Volumen des linken Ventrikels nimmt jedoch nicht zu, während der rechte Ventrikel eine ausgeprägte Dilatation zeigt. Dies spricht dafür, daß bei diesen Patienten Vorlast, Dehnbarkeit und Funktion des linken Ventrikels maßgeblich durch den Füllungszustand des rechten Ventrikels beeinflußt werden, durch Ausbuchtung des Septums und Perikardbehinderung (s. auch S. 241-242, Abschn. „Spezielle Aspekte bei der Behandlung der rechtsventrikulären Dysfunktion bei akuter septischer Kardiomyopathie“).

Sauerstofftransportparameter: die Prognose eines Patienten scheint günstig, wenn durch alleinige initiale Volumensubstitution ein Herzindex von $\geq 4,51 / \mathrm{min}^{2}$ mit einem Sauerstoffangebot $\left(\mathrm{DO}_{2}\right)$ von $\geq 600 \mathrm{ml} / \mathrm{min} / \mathrm{m}^{2}$ und damit ein $\mathrm{VO}_{2}$ von $\geq 170 \mathrm{ml} / \mathrm{min} / \mathrm{m}^{2}$ erzielt werden kann [11]. In etwa 30-40\% gelingt mittels initialer Volumensubstitution eine ausreichende hämodynamische Stabilisierung (s. unten; [46]). Für die angestrebten $\mathrm{DO}_{2}$ - und $\mathrm{VO}_{2}$-Werte dürfte dies allerdings nur in etwa $10-20 \%$ der Fall sein [11] v.a. wegen der häufig nicht genügend besserbaren Sauerstoffextraktionseinschränkung und -verwertungsstörung und weniger wegen eines nicht ausreichend steigerbaren Sauerstoffangebots s. auch S. 223, Katecholamine und supranormales $\mathrm{O}_{2}$-Angebot: mit mehr Sauerstoff allein ist es nicht getan).

Hämatokritwert: Zielkriterium der Volumengabe ist nicht nur eine Zunahme des systemischen Blutflusses, sondern auch eine Steigerung des $\mathrm{O}_{2}$-Transports und der $\mathrm{O}_{2}$-Aufnahme ins Gewebe; die Sauerstoffaufnahmerate wird wiederum mitbestimmt von der Hämoglobinkonzentration und damit von Hämatokrit und von der Blutviskosität. Derzeit wird die Einstellung eines Hämatokrits von 30-35\% empfohlen, ohne daß jedoch bisher eine ausreichende Validierung dieser Empfehlung vorliegt [46].

Ob kolloidale oder kristalloide Lösungen zur Volumensubstitution bei septischen Patienten besser geeignet sind, wird seit langem kontrovers diskutiert; die Art der Lösung scheint allerdings für den Therapieerfolg nur eine untergeordnete Rolle zu spielen. Unterschiede bzgl. Morbidität und Letalität konnten für verschiedene Flüssigkeitsregimes bisher nicht eindeutig gezeigt werden ([37] S. 252-260; ausführliche Diskussion und Literaturangaben in [46]).

Kristalloide Lösungen sind kostengünstig, leicht zu lagern, steigern ausreichend die Diurese und können zusätzlich extravasale Flüssigkeitsverluste bei Dehydratationszuständen ersetzen; nachteilig sind das Auftreten ausgeprägter peripherer Ödeme und die relativ kurze hämodynamische Wirksamkeit. Am häufigsten kommen physiologische (0,9\%ige) Kochsalzlösung und Vollelektrolyte (z. B. Ringer-Laktat) zum Einsatz, die sich beide gleichermaßen im Intravasalraum und im Interstitium verteilen; nach einer Stunde findet sich aber nur noch weniger als $25 \%$ des infundierten Volumens in der Zirkulation. Beide Lösungen senken den kolloidosmotischen Druck. Im Vergleich zu kolloidalen Lösungen muß etwa das Vier- bis Fünffache des intravasalen Flüssigkeitsdefizits an kristal- 
loider Flüssigkeit zur Erzielung einer vorübergehenden Normovolämie infundiert werden. 5\%ige Glukoselösung findet sich eine Stunde nach Infusion nur noch zu 8\% im Intravasalraum; sie erhöht neben dem Volumen des Extrazellulärraums unerwünschterweise auch das des Intrazellulärraums, infolge des Wassereinstroms in die Zellen zum Ausgleich des infusionsbedingten osmotischen Gradienten. Sie sollte deshalb für diese Indikation nicht verwendet werden.

Kolloidale Lösungen (Albumin, Hypdroxyethylstärke, Dextran, Gelatine; Tabelle 11.2) verbleiben zunächst vorwiegend im Intravasalraum und stellen dort den plasmaonkotischen Druck wieder her. Sie führen demzufolge in geringerem Ausmaß zu peripheren Ödemen, und es reichen kleinere Volumina zur Substitution aus als beim Einsatz von kristalloiden Lösungen. Nachteile sind neben den hohen Kosten die bekannten, substanzeigenen Nebenwirkungen (s. unten). Daß kolloidale Lösungen v. a. bei der Sepsis mit ihrer erhöhten Kapillarpermeabilitat das Auftreten eines Lungenödems fördern, ist viel diskutiert, aber bisher nicht gesichert worden.

Albumin findet als 5\%ige (kolloidosmotischer Druck ca. $20 \mathrm{~mm} \mathrm{Hg}$ ) und als 20-25\%ige Lösung (kolloidosmotischer Druck ca. 80-100 mm Hg) Verwendung, es verbleibt relativ lange im Intravasalraum (mehr als $90 \%$ nach $2 \mathrm{~h} \mathrm{[45]).} \mathrm{Bei}$ Hypovolämie ist initial eher die 5\%ige Lösung angebracht; bei ödematösen Patienten kann die Verwendung der hyperonkotischen Albuminlösung eine erwünschte Flüssigkeitsverschiebung aus dem Interstitium in den Intravasalraum bewirken. Zumindest bei einem Serumalbumin von weniger als $2 \mathrm{~g} / \mathrm{dl}$ empfiehlt sich die Gabe von Albumin [26]. Es ist jedoch nicht sinnvoll, eine Hypalbuminämie als Folge eines kapillaren Lecks - wie bei der Sepsis - mit Albumin vollständig auszugleichen, da dieses mit einer Halbwertszeit von 1-6 h aus dem Intravasal- in den Extravasalraum abwandert. Der Absolutwert des kolloidosmotischen Drucks hat sich dagegen als Parameter zur Albuminsubstitution nicht durchgesetzt.

Unerwünschte, in der Regel milde Nebenwirkungen - Fieber, Schüttelfrost, Urticaria - treten mit einer Häufigkeit von etwa $0,5 \%$ auf; die Blutgerinnung wird nicht beeinträchtigt. Bei der Infusion großer Albuminmengen kann es zu einer Senkung des ionisierten Plasmakalziums kommen.

Dextrane sind hochmolekulare lineare Polysaccharide mit vereinzelten Seitenketten, gelöst in physiologischer Kochsalzlösung. Sie werden entsprechend ihrer Molekularmasse entweder direkt $(\mathrm{MG}<50 \mathrm{kD})$ oder nach Enzymdegradation bevorzugt renal eliminiert. Durch den hohen kolloidosmotischen Druck füllt die 10\%ige Dextran-40-Lösung den Intravasalraum durch einen ausgeprägten Einstrom aus dem Interstitium auf, was im Schock mit gestörter Mikrozirkulation erwünscht, bei einem depletierten Extrazellulärraum jedoch eher unerwünscht ist.

Dextran 40 reduziert die Geldrollenbildung der Erythrozyten, und es soll auch die Gewebeoxygenierung verbessern.

Hydroxyethylstärkepräparationen (HES) sind ebenfalls Polysaccharide. Je höher ihre Molekularmasse und der durchschnittliche Substitutionsgrad mit Hydroxyethylgruppen ist, um so länger ist die Verweildauer im Organismus und 
die Volumenwirkung. Das Ausmaß der Substitution der Glukose mit Hydroxyethylgruppen bestimmt die Degradierbarkeit der HES-Moleküle durch plasmatische ( $\alpha$-Amylase) und v.a. lysosomale Glykosidasen. Kleinere Bruchstücke werden über die Nieren ausgeschieden, größere im retikuloendothelialen System phagozytiert. Mit Ausnahme des niedermolekularen HES 40/0,5 rekrutieren die anderen HES-Lösungen Flüssigkeit aus dem Extrazellulärraum (Volumenfülleffekt > 1). Der Volumenzweiteffekt beruht auf einer Zunahme onkotisch wirksamer Teilchen infolge intravasaler Degradation höhermolekularer HES-Anteile durch Glykosidasen zu kleineren Bruchstücken; er erreicht ca. 60 min nach Infusion sein Maximum.

Sowohl Dextranen als auch HES werden neben der Volumenwirkung zusätzliche günstige Wirkungen im Sinne der Prävention eines Multiorganversagens zugeschrieben: Dämpfung aktivierter Kaskadensysteme, Milderung der Sequestration aktivierter Leukozyten, Abschwächung immunologischer Dysbalancen (Zitate in [45]).

Gelatinelösungen (Oxypolygelatine, modifizierte Gelatine und harnstoffvernetzte Gelatine) werden aufgrund ihrer verhältnismäßig niedrigen Molmassen relativ rasch renal eliminiert und steigern die Diurese. Sie sind fast isoonkotisch zu Plasma und bewirken deswegen trotz des hohen Wasserbindungsvermögens keine Volumenexpansion. Zur Erzielung und zum Erhalt einer Normovolämie muß daher beim Einsatz von Gelatinepräparaten im Vergleich zu Dextran- und HES-Lösungen primär höher dosiert und häufiger nachinfundiert werden.

Der Einsatz künstlicher Kolloide setzt die Kenntnis ihrer Nebenwirkungen voraus [45].

Anaphylaktischelanaphylaktoide Unverträglichkeitsreaktionen (UVR; 0,1$2 \%$, vermutlich bei bereits bestehender sympathoadrenerger und Streßreaktion deutlich niedriger) - mit Symptomen harmloser kutaner Reaktionen über Kreislaufreaktionen und Bronchospasmus bis zu lebensbedrohlichen Herz-Kreislaufund Atemstillständen - sind für alle im Handel befindlichen künstlichen Kolloide beschrieben. Die Dextran-UVR beruht auf einer Immunkomplexanaphylaxie infolge präexistenter, mit Dextran kreuzreagierender Antikörper, vornehmlich Ig $\mathrm{G}_{2}$-Antikörper in hohen Titerstufen. Nach Vorgabe von $20 \mathrm{ml}$ Dextran MG 1000 (Promit; Prinzip der Haptenhemmung) treten Dextran-UVR nicht wesentlich häufiger auf als nach anderen Kolloiden. Bei Gelatine-UVR konnte eine direkte Histaminausschüttung nachgewiesen werden (zumindest mitbedingt durch einen vom Hersteller zwischenzeitlich beseitigten Überschuß an Vernetzungsmittel). Sowohl Häufigkeit als auch Schweregrad dieser UVR läßt sich durch Vorbehandlung mit Histamin- $\mathrm{H}_{1}$ - und $\mathrm{H}_{2}$-Rezeptorenblockern senken. HES-UVR sind in ihrer Ursache bisher nicht geklärt. Höhergradige Reaktionen konnten bislang nicht auf die alleinige Verabreichung, insbesondere von neueren HES-Präparationen (HES 200), zurückgeführt werden. Die im Vergleich sehr gute Verträglichkeit ist möglicherweise auf die molekulare Strukturähnlichkeit mit Glykogen zurückzuführen [45].

Gerinnungsstörungen können bei allen künstlichen Kolloiden nach hohen Dosen als Dilutionskoagulopathie auftreten. Spezifische, qualitativ gleichsinnige 
inhibitorische Wirkungen auf die Hämostase verursachen aber nur Dextran und HES, erstere wesentlich ausgeprägter: Dämpfung der primären Hämostase durch Coating-Effekte auf Endothel und Thrombozyten; dosisabhängige Inhibierung der plasmatischen Gerinnung durch Interaktion mit Gerinnungsfaktoren, insbesondere mit sämtlichen Faktor-VIII-Qualitäten; sowie Erleichterung der Gerinnselauflösung durch die endogene Fibrinolyse infolge einer veränderten Fibrinpolymerisation. Demzufolge wird eine Dosislimitierung von derzeit 1,5 g/kgKG Dextran oder HES pro Tag empfohlen. Für HES wird derzeit eine Anhebung dieser Begrenzung diskutiert; für Gelatinepräparate gelten keine Dosisbeschränkungen [44].

Nach Gabe von Dextran, vornehmlich des hyperonkotischen Dextran 40, kann bei Exsikkose und Antidiurese eine Beeinträchtigung der Nierenfunktion als Folge eines Anstiegs der Urinviskosität des Primärharns auftreten: durch Verabreichung von Elektrolytlösungen läßt sich bei dieser reversiblen Nierenfunktionseinschränkung eine adäquate Diurese wiederherstellen.

Beim Vergleich kristalloider und kolloidaler Lösungen sind folgende Aspekte von Interesse (ausführliche Diskussion und Literaturangaben in [46].

Hämodynamik: Zweifellos läßt sich mit beiden Lösungen eine adäquate Volumensubstitution des Sepsispatienten erzielen, allerdings werden mit kristalloiden Lösungen 2- bis 4mal größere Volumina benötigt (stärkere Gewichtszunahme und Ödemneigung der Kranken) als mit kolloidalen, und es dauert länger bis zur Erzielung der hämodynamischen Stabilität. Einige Zahlen sollen dies untermauern: bei kritisch Kranken führt die Gabe von $500 \mathrm{ml}$ Albumin $5 \%$ bzw. Dextran $70 \mathrm{zu}$ einer Zunahme des Intravasalvolumens um jeweils 600-700 ml, und von $500 \mathrm{ml}$ Dextran 40 sogar um mehr als $1 \mathrm{l}$; dagegen hat die Infusion von 11 Ringer-Laktat eine Plasmavolumenzunahme von weniger als $150 \mathrm{ml}$ zur Folge (Zitat 36 in [45]. Bei postoperativen Patienten steigern je 11 Dextran 70, 6\% HES hochmolekular, 5\% Albumin bzw. Kochsalz das Plasmavolumen um 790, 710, 490 bzw. $180 \mathrm{ml}$ (Zitat 37 in [46]). In einem Cross-over-Vergleich bei kritisch Kranken erzielte die Gabe von $100 \mathrm{ml}$ Albumin 25\% eine Zunahme des Plasmavolumens $45 \mathrm{~min}$ nach Infusionsende um $465 \mathrm{ml}$, nach 11 Ringer-Laktat waren es dagegen kurzfristig maximal $194 \mathrm{ml}$ (Zitat 54 in [46]). Wesentliche Verbesserungen der Hämodynamik und des Sauerstofftransports korrelieren eindeutig mit der Plasmaexpansion, sie sind nach Gabe kristalloider Lösungen entweder gar nicht (Zitat 54 in [46]) oder wesentlich schwächer (Zitat 36 in [46]) als nach Infusion kolloidaler Lösungen nachweisbar.

Die Wirksamkeit der einzelnen kolloidalen Lösungen untereinander scheint vergleichbar (Tabelle 11.2), die Wirkdauer der HES-Lösungen dagegen länger als die des 5\%igen Albumin (Zitate 58-61 in [46]).

Lungenfunktion: Bei der Diskussion um die ideale Volumenersatzlösung spielt die potentielle Gefahr der Auslösung eines Lungenödems eine entscheidende Rolle. Verfechter des Einsatzes kolloidaler Lösungen führen an, daß kristalloide Flüssigkeiten den kolloidosmotischen Druck (KOD) nachhaltig erniedrigen und damit diese Gefahr hervorrufen. Verfechter des Einsatzes kristalloider Lösungen fürchten dagegen beim Einsatz kolloidaler Lösungen einen verstärkten 
Abstrom kolloidosmotisch wirksamer Moleküle durch die geschädigte alveolokapilläre Membran ins Interstitium, mit einem Anstieg des extravaskulären KOD und damit der Gefahr der Ausbildung oder Verstärkung eines Lungenödems.

Sowohl eine Erniedrigung des KOD als auch ein Anstieg des mikrovaskulären hydrostatischen Drucks kann das Auftreten eines Lungenödems begünstigen, wobei dem pathologischen Anstieg des hydrostatischen Drucks jedoch eine wesentlich entscheidendere Bedeutung zukommt als dem Abfall des KOD. Um das Risiko des Auftretens eines Lungenödems besser abschätzen zu können, wurde der Terminus „kolloidosmotischer Druck - Pulmonalkapillardruck - Gradient“ eingeführt (COP-PAW-Gradient). Die Annahme, ein niedriger COP-PAW-Gradient disponiere zum Auftreten eines Lungenödems, ist jedoch nicht unwidersprochen geblieben (Diskussion in [46]). Die Bestimmung des Lungenwassers, der intrapulmonalen Shuntfraktion und des alveoloarteriellen Sauerstoffgradienten sind weitere Parameter, die neben klinischen und röntgenologischen Zeichen zur Beurteilung der Gefahr eines Lungenödems unter Volumensubstitution Verwendung finden. Bei der Wertung der insgesamt spärlichen klinischen Studien (Übersicht und Literaturangaben in [46]) wird evident, daß kolloidale Lösungen zu keiner Verschlechterung des intrapulmonalen Shuntanteils, der Lungenfunktion, des extravasalen Lungenwassers und des transmikrovaskulären Flusses sowohl hoch- als auch niedermolekularer Substanzen zu führen scheinen. Überzeugende Vor- oder Nachteile kristalloider vs. kolloidaler Lösungen in bezug auf die Lunge wurden bisher in kontrollierten Untersuchungen nicht aufgezeigt.

Spezifische Organperfusion: In tierexperimentellen Sepsismodellen wurde die Wirksamkeit kristalloider und kolloidaler Lösungen hinsichtlich einer Steigerung der Durchblutung spezifischer Organe verglichen. Aufgrund der uneinheitlichen Ergebnisse und der bisher fehlenden klinischen Studien ergeben sich daraus noch keine differentialtherapeutischen Aspekte [46].

\section{Erythrozytentransfusionen}

Bei kritisch Kranken ist eine mäßige Anämie infolge eines okkulten Blutverlustes und einer supprimierten Erythropoese nicht selten. Übereinstimmung besteht darüber, daß Patienten mit akuter Anämie und einem Hämoglobinwert von 70 $\mathrm{g} / 1$ und darunter - entsprechend den allgemeinen Transfusionsempfehlungen (Zitate 11 und 12 in [43] - mit Erythrozytentransfusionen substituiert werden sollten. Handelt es sich dabei um Risikopatienten bzgl. einer Myokard- oder Hirnischämie (koronare Herzkrankheit, hämodynamisch relevante Klappenvitien, manifeste Herzinsuffizienz, zerebrovaskuläre Insuffizienz) und liegen außerdem klinische Zeichen einer Sauerstoffminderversorgung trotz Normovolämie vor (Synkope, Dyspnoe, orthostatische Hypotonie, Tachykardie, Angina pectoris, transiente ischämische Attacke), so ist nach diesen Empfehlungen auch bei einem Hämoglobinwert über $70 \mathrm{~g} / \mathrm{l}$ die Gabe von Erythrozytenkonzentraten gerechtfertigt, mit entsprechender Erfolgskontrolle nach jeder Konserve; vor der 
Transfusion sollte mit ausreichend Flüssigkeit das Intravasalavolumen aufgefüllt werden, um die bei Anämie notwendige Hyperzirkulation zu gewährleisten. Es gibt allerdings derzeit keinen gut belegten Schwellenwert für den Hämatokritoder Hämoglobinwert, ab dem bei septischen Patienten eine Erythrozytentransfusion indiziert ist. Aufgrund des erhöhten Sauerstoffbedarfs bei gleichzeitig reduzierter Kreislaufreserve können Sepsispatienten als „Sauerstoffrisikopatienten" angesehen werden, da sie nicht in der Lage sind, die bei Anämie erforderliche Steigerung des Herzzeitvolumens zur Deckung des Sauerstofftransportes adäquat aufzubringen [43]. Klinische Untersuchungen stützen bis zu einem gewissen Grad die Annahme, daß Erythrozytentransfusionen bei septischen Patienten das Sauerstoffangebot und den Sauerstoffverbrauch steigern. Daraus resultiert die Empfehlung, bei Patienten mit Sepsis den Hämoglobingehalt auf über $100 \mathrm{~g} / \mathrm{l}$ anzuheben $[42,43]$.

Hyperton(-hyperonkotische) Lösungen

Auch Infusionen mit Glukose, Insulin und Kalium werden beim septischen Schock eingesetzt ([37], S. 252-260; [45, 46]). Der Stellenwert weiterer hypertoner Lösungen (1,7\%ige, 3\%ige, 5\%ige und 7,5\%ige Kochsalzlösung) und insbesondere der einer hyperton-hyperonkotischen Kochsalzkolloidlösung („small volume resuscitation“, z. B. $4 \mathrm{ml} / \mathrm{kgKG} \mathrm{7,2 \%} \mathrm{NaCl} / 10 \%$ Dextran 60 oder HES 200/0,5 [45]) wird derzeit in experimentellen und klinischen Studien untersucht ([27] 104-118; [37] S 252-260; [51] S 186-196; [45, 46]). Vor allem bei Trauma-I Schockpatienten in der initialen Therapiephase könnten sie von Bedeutung sein, mit den Vorteilen eines geringeren zu infundierenden Volumens, einer raschen Besserung der Hämodynamik, einer Senkung des intrakraniellen Drucks und einer Optimierung der Mikrozirkulation infolge einer Reduktion der Endothelschwellung. Auch in einem Endotoxintiermodell haben sie ihre Überlegenheit gegenüber isotonen kristalloiden Lösungen hinsichtlich der Verbesserung des Herzzeitvolumens und des Sauerstofftransports gezeigt (Zitat 87 in [46]); dagegen war in einer anderen tierexperimentellen Sepsisstudie der Vorteil allenfalls marginal (Zitat 88 in [46]). Um Rückverteilungsvorgänge zu vermeiden, muß sich allerdings rasch (binnen $20 \mathrm{~min}$ ) eine konventionelle Volumentherapie anschließen, damit das erzielte Ergebnis erhalten bleibt [45]. Kontrollierte Studien über den Einsatz hyperton-hyperonkotischer Lösungen bei Patienten mit septischem Schock wurden bisher noch nicht vorgelegt.

Katecholamine (weiterführende Literatur in $[38,40,56]$ )

\section{Grundlagen}

Die Therapie mit Katecholaminen und Sympathomimetika (im weiteren als Katecholamine bezeichnet) bei Patienten mit Sepsis/septischem Schock und Multiorganversagen hat zum Ziel, die Herz-Kreislauf-Schädigung zu kompensieren 
und damit die Durchblutung und die $\mathrm{O}_{2}$-Versorgung der Vitalorgane sicherzustellen (s. Kap. 10). Es handelt sich dabei um eine symptomatische, nicht um eine kausale Therapie.

Katecholamine entfalten ihre physiologischen und pharmakologischen Wirkungen durch Besetzung und Stimulation von Rezeptoren: am Herzen vorwiegend $\beta_{1}$-Adrenozeptoren und an den Gefäßben $\alpha_{1}$ - und $\beta_{2}$-Adrenozeptoren sowie Dopamin (DA-1 und DA-2)-Rezeptoren.

\section{Adrenozeptoren und Dopaminrezeptoren des Herz-Kreislauf-Systems}

\section{Herz}

- $\beta_{1}$-Adrenozeptoren:

positiv inotrop und chronotrop;

- $\beta_{2}$ - und $\alpha_{1}$-Adrenozeptoren:

positiv inotrop (untergeordnete Bedeutung);

Gefäße

- $\alpha_{1}$-Adrenozeptoren:

Vasokonstriktion (Arterien und Venen);

- $\beta_{2}$-Adrenozeptoren:

Vasodilatation (Arterien);

- Dopamin (DA)-Rezeptoren:

- DA-1 (postsynaptisch): Vasodilatation (vorwiegend Nieren- und Mesenterialgefäße)

- DA-2 (präsynaptisch): „passive Vasodilatation“ durch Hemmung der Noradrenalinfreisetzung.

Die Differentialtherapie mit Katecholaminen wird primär nicht durch unterschiedliche pharmakokinetische Eigenschaften bestimmt, sondern durch die unterschiedlichen Affinitäten der einzelnen Substanzen zu diesen verschiedenen Rezeptorarten (Tabelle 11.3). Dopamin und Dobutamin sind dabei in der Regel „Katecholamine der ersten Wahl“.

Dopamin in niedriger Dosierung stimuliert die Dopaminrezeptoren und wirkt dadurch v. a. auf die Nieren- und Mesenterialgefäße vasodilatierend (Steigerung der Nierenperfusion). Die gleichzeitige Stimulation $\operatorname{der} \beta_{1}$-Adrenozeptoren ist für die positiv-inotrope und positiv-chronotrope Wirkung dieser Substanz verantwortlich. Bei hohen Dopaminkonzentrationen dominiert die vasokonstringierende $\alpha$-Adrenozeptorwirkung über die vasodilatierende dopaminerge Wirkung - mit dem Nettoeffekt einer Vasokonstriktion auch der Nierenarterien.

Das für den klinischen Einsatz verfügbare Dobutamin ist ein Razemat aus 2 Enantiomeren; das (-)-Isomer bewirkt überwiegend eine $\alpha$-Adrenozeptorstimulation, das (+)-Isomer überwiegend eine $\beta_{1}$ - und auch eine $\beta_{2}$-Adrenozeptorstimulation. Der Nettoeffekt ist eine ausgeprägte positiv-inotrope Wirkung - bei nur geringer Frequenzbeeinflussung - und eine geringe Senkung des Gefäßwiderstands, bei weitgehend unverändertem Blutdruck. 
Tabelle 11.3. Herz- und Gefäßwirkungen von Sympathomimetika. (Mod. nach Parrillo [26])

\begin{tabular}{|c|c|c|c|c|c|}
\hline \multirow{2}{*}{$\begin{array}{l}\text { Substanz } \\
\text { Dosierung }\end{array}$} & \multicolumn{2}{|c|}{ Herzwirkung } & \multicolumn{3}{|c|}{ Gefäßwirkung } \\
\hline & $\begin{array}{l}\beta_{1} \\
\text { Herz- } \\
\text { frequenz }\end{array}$ & $\begin{array}{l}\beta_{1} \\
\text { Kontrak- } \\
\text { tilität }\end{array}$ & $\begin{array}{l}\alpha \\
\text { Vasokon- } \\
\text { striktion }\end{array}$ & $\begin{array}{l}\boldsymbol{\beta}_{2} \\
\text { Vaso- } \\
\text { dilatation }\end{array}$ & $\begin{array}{l}\text { Dopamin- } \\
\text { erg }\end{array}$ \\
\hline \multicolumn{6}{|l|}{ Dopamin $^{a}$} \\
\hline $1-10 \mu \mathrm{g} / \mathrm{kg} / \mathrm{min}$ & $2+$ & $2+$ & $0 / 2$ & $2+$ & $4+$ \\
\hline$>10 \mu \mathrm{g} / \mathrm{kg} / \mathrm{min}$ & $2+$ & $2+$ & $2-3+$ & & $4+$ \\
\hline \multicolumn{6}{|l|}{ Dobutamin } \\
\hline $1-10 \mu \mathrm{g} / \mathrm{kg} / \mathrm{min}$ & $1+$ & $4+$ & $1+$ & $2+$ & 0 \\
\hline \multicolumn{6}{|l|}{ Noradrenalin } \\
\hline $2-8 \mu \mathrm{g} / \mathrm{min}$ & $2+$ & $2+$ & $4+$ & 0 & 0 \\
\hline \multicolumn{6}{|l|}{ Adrenalin } \\
\hline $1-8 \mu \mathrm{g} / \mathrm{min}$ & $4+$ & $4+$ & $4+$ & $3+$ & 0 \\
\hline \multicolumn{6}{|l|}{ Isoproterenol } \\
\hline $1-4 \mu \mathrm{g} / \mathrm{min}$ & $4+$ & $4+$ & 0 & $4+$ & 0 \\
\hline $\begin{array}{l}\text { Phenylephrin } \\
20-200 \mu \mathrm{g} / \mathrm{min}\end{array}$ & 0 & 0 & $4+$ & 0 & 0 \\
\hline $\begin{array}{l}\text { Dopexamin } \\
1-6 \mu \mathrm{g} / \mathrm{kg} / \mathrm{min}\end{array}$ & $1+$ & $1+$ & 0 & $3+$ & $2+$ \\
\hline
\end{tabular}

${ }^{a} \beta_{1} / \beta_{2}-$ Wirkung ab ca. $2-3 \mu \mathrm{g} / \mathrm{kg} / \mathrm{min} ; \alpha$ - Wirkung ab ca. $2-3 \mu \mathrm{g} / \mathrm{kg} / \mathrm{min}$; vasokonstriktorische $\alpha$-Wirkung überwiegt dopaminerge Vasodilatation der Nieren- und Splanchnicusgefäße.

Beim Noradrenalin steht neben der positiv-inotropen $\boldsymbol{\beta}_{1}$-Adrenozeptorwirkung v. a. die Vasokonstriktion durch $\alpha$-Adrenozeptorstimulation im Vordergrund; sie ist verantwortlich für den ausgeprägten Blutdruckanstieg. Die Bindungsaffinität zu den $\beta_{2}$-Adrenozeptoren ist wesentlich geringer als die zu den $\beta_{1}$ Adrenozeptoren, so daß eine vasodilatierende Wirkung fehlt.

Adrenalin stimuliert in gleicher Weise die $\boldsymbol{\beta}_{1}$-Adrenozeptoren des Herzens (ausgeprägte positiv-inotrope und -chronotrope Wirkung) wie auch die $\beta_{2^{-}}$ Adrenozeptoren der Gefäße (Vasodilatation). In höheren Konzentrationen besetzt und aktiviert Adrenalin dann auch die $\alpha$-Adrenozeptoren der Gefäße, weshalb bei niedrigen Konzentrationen eine Abnahme des Gefäßwiderstands, bei hohen eine Zunahme des Gefäßwiderstands mit Blutdruckanstieg resultiert. Adrenalin wird als besonders arrhythmogen angesehen. Der allen Katecholaminen eigene, den Sauerstoffverbrauch steigernde „calorigene" Effekt sei beim Adrenalin besonders gravierend, und darüber hinaus müsse mit einer Durchblutungsminderung im Leber-Splanchnicus-Gebiet gerechnet werden [38]. Die im Schrifttum empfohlene Zurückhaltung beim Einsatz - nur zur Therapie einer 
ausgeprägten Hypotonie bei gleichzeitig hohem Schlagvolumen - steht in gewissem Widerspruch zu der praktischen Erfahrung, daß mit Adrenalin häufig auch dann noch eine Stabilisierung des Herz-Kreislauf-Systems zu erreichen ist, wenn die anderen genannten Katecholamine keine ausreichende Wirkung mehr zeigen.

$\mathrm{Zu}$ erwähnen ist weiterhin Dopexamin, ein Dopaminabkömmling, über dessen Anwendung bisher nur begrenzte Erfahrungen vorliegen. Es stimuliert - schwächer als Dopamin - Dopaminrezeptoren (überwiegend DA-1) und - wesentlich stärker als Dopamin - $\boldsymbol{\beta}_{2}$-Adrenozeptoren; darüber hinaus ist es ein schwacher $\beta_{1}$-Adrenozeptoragonist, während $\alpha$-Adrenozeptoren durch Dopexamin nicht aktiviert werden. Daraus resultieren ein gesteigerter renaler Blutfluß sowie eine Zunahme des Herzzeitvolumens aufgrund der Nachlastsenkung infolge Vasodilatation. Weiterhin wird eine zusätzliche milde positiv-inotrope Wirkung hervorgerufen: durch Stimulation myokardialer $\boldsymbol{\beta}_{2}$-Adrenozeptoren, durch Potenzierung der Wirkung endogenen Noradrenalins infolge Hemmung der Wiederaufnahme sowie durch eine Aktivierung des Barorezeptorreflexes.

Durch Dopexamin $(1,0-6,0 \mu \mathrm{g} / \mathrm{kg} / \mathrm{min}$ weiterführende Literatur in [38]) kommt es bei Patienten mit septischem Schock akut zu einem Anstieg des Herzindex (von 4,0 auf 5,0 1/ $/ \mathrm{m}^{2}$ ) und der Herzfrequenz (von 120 auf 130/min) und zu einem Abfall des systemischen Gefäßwiderstands (von 700 auf $550 \mathrm{dyn} \cdot \mathrm{cm}^{-5} \cdot \mathrm{s}$ ). Mittlerer Blutdruck, Pulmonalisdruck und Pulmonalkapillardruck ändern sich nicht signifikant; während einer 48stündigen Infusionsdauer muß mit einer gewissen Wirkungsabschwächung gerechnet werden (Zitat 8 in [56]). In chirurgischen Hochrisikopatienten steigerte Dopexamin das $\mathrm{O}_{2}$-Angebot von $399 \mathrm{ml} /$ $\mathrm{min} \cdot \mathrm{m}^{2}$ auf $597 \mathrm{ml} / \mathrm{min} \cdot \mathrm{m}^{2}$ perioperativ und reduzierte die postoperative Letalität um 75\% (Zitat 47 in [38]). Reinhardt [38] stuft die vorliegenden Daten als erfolgversprechend ein. Er geht davon aus, daß Dopexamin bei der Behandlung septischer Patienten nützlich sein könnte. Er stellt jedoch fest, daß z. Z. zu wenige Ergebnisse vorliegen, um bereits Therapieempfehlungen zu geben und Indikationen für den Einsatz von Dopexamin zu stellen. Eine selektiv günstige (Zitate 44 und 45 in [38]), aber auch eine ungünstige [38] Wirkung auf das Nieren-Splanchnikus-Gebiet wird diskutiert.

Der differentialtherapeutische Nutzen dieser unterschiedlichen Rezeptoraffinität wurde von Löllgen u. Meuret [18] anschaulich charakterisiert (Abb. 11.6): Bei vergleichbarer positiv-inotroper Wirkung beeinflussen die 4 aufgeführeten Katecholamine Herzfrequenz, Blutdruck und Gefäßwiderstand sowie den linksventrikulär-enddiastolischen Füllungsdruck in unterschiedlicher Weise: Adrenalin wirkt am stärksten, Noradrenalin am wenigsten positiv-chronotrop; v. a. Noradrenalin erhöht den Gefäßwiderstand und damit den Blutdruck; in höheren Konzentrationen als den in Abb. 11.6 aufgeführten trifft dies allerdings auch für Dopamin und Noradrenalin zu. Die in Abb. 11.6 gezeigten Katecholaminwirkungen setzen ein intaktes Herz-Kreislauf-System voraus: bei Sepsis und septischem Schock können Desensibilisierungsprozesse und Toxin- und Mediatorschädigungen das Ansprechen auf Katecholamine ganz erheblich beeinträchtigen (s. unten). 

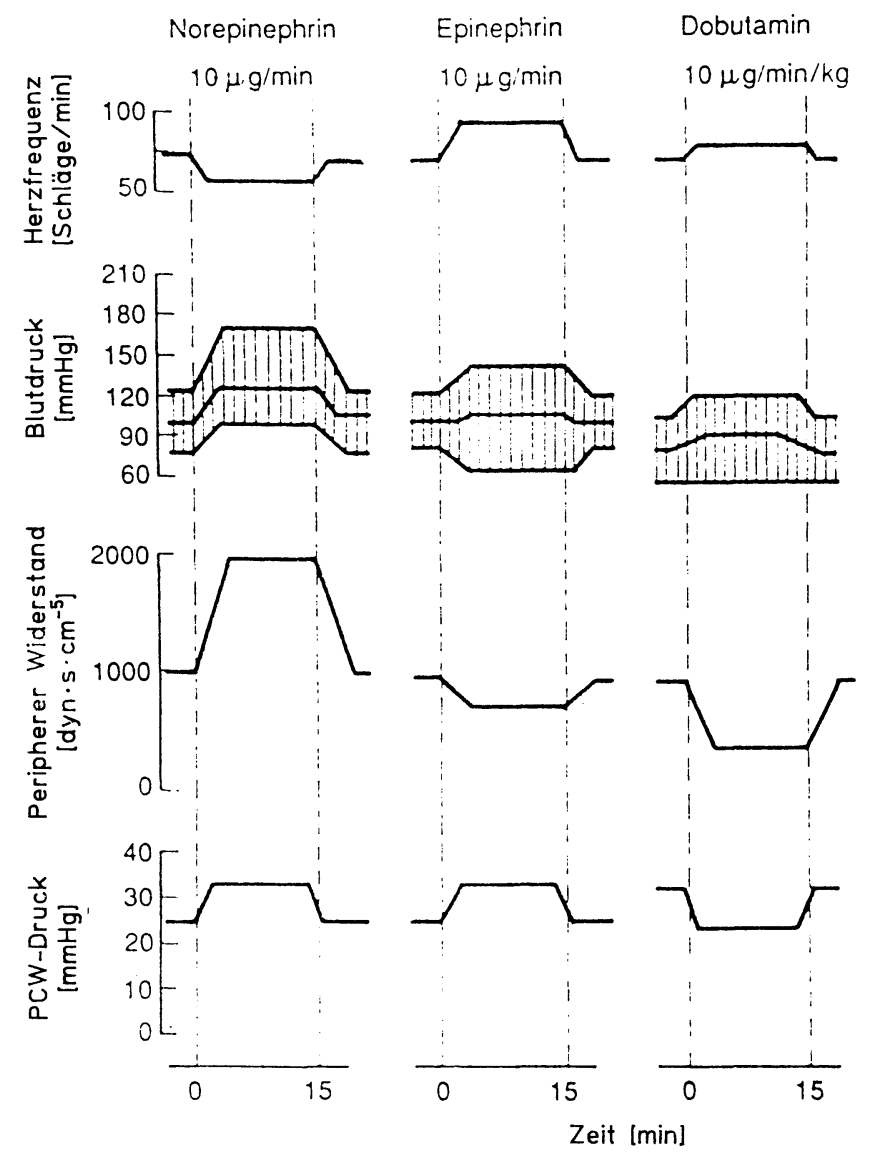

Dopamin
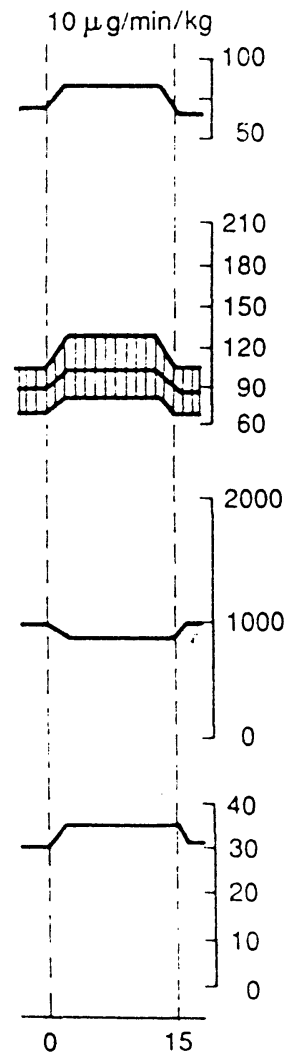

Abb. 11.6. Schematische Darstellung der hämodynamischen Wirkungen der verschiedenen Sympathomimetika („Norepinephrin“ = Noradrenalin; „Epinephrin“ = Adrenalin; „PCW“ = Pulmonalkapillardruck). (Aus Löllgen u. Meuret [18])

Dopamin und Dobutamin im Vergleich:

Füllungsdruck und Wandspannung des linken Ventrikels

Während Dobutamin den linksventrikulär-enddiastolischen Druck entweder unbeeinflußt läßt oder ihn sogar geringfügig senkt, wird er durch Dopamin meistens etwas gesteigert. Die Ursache für letzteres dürfte ein erhöhter venöser Rückstrom durch eine $\alpha$-Adrenozeptor-vermittelte Venokonstriktion sein ([51], S. 186-196).

Wahrscheinlich als Konsequenz dieser dopamininduzierten Venokonstriktion waren im experimentellen septischen Schock bei Dobutamin größere Flüssigkeitsmengen als bei Dopamin erforderlich, um eine adäquate Volumenauffüllung zu bewirken. Durch die Flüssigkeitssubstitution ließen sich mit Dobutamin Herzzeitvolumen und $\mathrm{O}_{2}$-Transport besser steigern als mit Dopamin. 
Über eine günstigere Wirkung des Dobutamins als die des Dopamins auf die rechtsventrikuläre Funktion kritisch Kranker wurde berichtet; desgleichen soll der pulmonale Gasaustausch (Shuntzunahme und/oder Ventilations-PerfusionsMißverhältnis mit resultierender Hypoxämie) durch Dobutamin weniger beeinflußt werden als durch Dopamin. Nach aortokoronarer Bypassoperation waren vergleichbare Dobutaminkonzentrationen wirksamer als Dopamin bzgl. des Herzzeitvolumens und der Inotropieparameter. Die linksventrikuläre Wandspannung stieg unter Dopamin an und blieb unter Dobutamin konstant. Da die Wandspannung eine wesentliche Determinante des myokardialen $\mathrm{O}_{2}$-Verbrauchs darstellt, würde Dobutamin v.a. bei koronarkranken Patienten dem Dopamin gegenüber den Vorteil des geringeren myokardialen $\mathrm{O}_{2}$-Verbrauchs bei gleicher oder sogar besserer Wirksamkeit besitzen. Die klinische Relevanz dieses Befunds ist jedoch noch Gegenstand der Diskussion (Zitate in [56]).

\section{Dopamin in „Nierendosis": Protektive Wirkung bisher nicht belegt!}

Das akute Nierenversagen ist in der Sepsis häufig, und es hat eine ungünstige Prognose. Der Dopaminrezeptor-vermittelten Steigerung der Nierenperfusion durch niedrigdosierte Dopamininfusionen $(0,5-2-3 \mu \mathrm{g} / \mathrm{kg} \cdot \mathrm{min})$ wird eine gewisse Nephroprotektion zugeschrieben, und zwar sowohl bei alleiniger Gabe von Dopamin, als auch in Kombination mit vasokonstriktorischen Katecholaminen wie Noradrenalin. Dieses sehr häufig praktizierte Vorgehen fußt auf tierexperimentellen Befunden [26] und kasuistischen Beobachtungen (Übersicht in [56]); letztere haben v. a. eine Steigerung der Diurese und Natriurese beschrieben. In kontrollierten Studien konnte jedoch durch Dopamin in „Nierendosis“ keinerlei nephroprotektiver Effekt und auch keine Prognoseverbesserung dokumentiert werden [22, 48]. Der nicht belegten protektiven Wirkung müssen potentiell ernste Nebenwirkungen dieser scheinbar harmlosen Therapie entgegengehalten werden: der Effekt der „Dopaminnierendosis“ beschränkt sich nämlich nicht nur auf die erwünschte Steigerung der Nieren- und Splanchnikusdurchblutung; es können ebenso bereits bei diesen niedrigen Dosierungen vasokonstriktorische und arrhythmogene Effekte auftreten; Gewebenekrose, Fingergangrän und Darmischämie mit verminderter Sauerstoffextraktion und gesteigerter bakterieller Translokation können die Folge sein, ebenso wie eine Zunahme pulmonaler Shunts, Tachykardien und Myokardischämien sowie eine Hemmung des Hypoxie-vermittelten Atemantriebs. Außerdem muß innerhalb von 2 bis 3 Tagen mit einer Toleranzentwicklung bzgl. des vasodilatierenden Effekts gerechnet werden (Literaturzusammenstellung in [48]). In Abwägung von nicht gesichertem Nutzen und belegtem potentiellen Risiko kann der routinemaßige Einsatz von niedrigdosiertem Dopamin zur Nephroprotektion bei Sepsispatienten derzeit nicht empfohlen werden $[38,42,48]$. 
Katecholamine und supranormales $\mathrm{O}_{2}$-Angebot:

mit mehr Sauerstoff allein ist es nicht getan!

Das Konzept der supranormalen $\mathrm{O}_{2}$-Versorgung von Patienten mit ARDS und Sepsis sowie anderen kritisch Kranken wird seit mehr als 20 Jahren propagiert und praktiziert (Literatur in [11]; s. auch Kap. 10). Es beruht auf der Annahme einer pathologischen - zu höheren $\mathrm{DO}_{2}$-Werten verschobenen - Abhängigkeit der $\mathrm{O}_{2}$ Aufnahme $\left(\mathrm{VO}_{2}\right)$ vom $\mathrm{O}_{2}$-Angebot/Transport $\left(\mathrm{DO}_{2}\right)$ bei diesen Patienten. Eine Besserung der $\mathrm{VO}_{2}$ ließe sich demzufolge über eine Erhöhung der $\mathrm{DO}_{2}$ erzielen, und dies wäre wiederum über eine Steigerung des Herzindex durch die positivinotropen Katecholamine möglich. Eine kürzlich durchgeführte Untersuchung [11] stellt dieses Konzept jedoch in Frage: 50 kritisch Kranke, überwiegend septische Patienten erhielten zur Erzielung eines supranormalen $\mathrm{O}_{2}$-Angebots (Zielkriterien: Herzindex $>4,5 \mathrm{l} / \mathrm{min} \cdot \mathrm{m}^{2} \mathrm{KOF} ; \mathrm{DO}_{2}>600 \mathrm{ml} / \mathrm{min} \cdot \mathrm{m}^{2} \mathrm{KOF}$; $\mathrm{VO}_{2}>170 \mathrm{ml} / \mathrm{min} \cdot \mathrm{m}^{2} \mathrm{KOF}$ ) eine Infusionstherapie mit Dobutamin, in z. T. sehr hoher Dosierung (5-200 $\mu \mathrm{g} / \mathrm{kgKG} \cdot \mathrm{min}$ !). Parallel dazu wurden 50 Patienten in konventioneller Weise behandelt (Dobutamingabe nur bei einem Herzindex $<2,8$ $\mathrm{l} / \mathrm{min} \cdot \mathrm{m}^{2} \mathrm{KOF}$ ). Zwar ließ sich mit der hochdosierten Dobutamingabe eine Steigerung des Herzindex und des $\mathrm{O}_{2}$-Angebots erzielen, der $\mathrm{O}_{2}$-Verbrauch stieg bei diesen Patienten dennoch nicht an. Auf die Prognose wirkte sich diese Form des supranormalen $\mathrm{O}_{2}$-Angebots überraschenderweise nicht nur nicht günstig, sondern sogar ungünstig aus: $54 \%$ der so behandelten Patienten verstarben, während die Letalitat der konventionell therapierten Patienten bei 34\% lag [11]. Das Erzwingen eines supranormalen $\mathrm{O}_{2}$-Angebots ,um jeden Preis“ - d. h. mit z.T. sehr hohen Katecholamindosen - scheint demzufolge nicht empfehlenswert [42].

\section{Katecholamintherapie und Toleranzentwicklung}

Die positiv-inotrope Wirkung sowohl der endogenen als auch der pharmakologisch applizierten Katecholamine wird vorwiegend durch Stimulation des $\beta_{1^{-}}$ Adrenozeptor-Adenylatzyklase-Systems vermittelt (Abb. 11.7). Die Besetzung des $\boldsymbol{\beta}_{1}$-Adrenozeptors in der Herzmuskelzellmembran mit einem Katecholaminmolekül fuhrt über die Aktivierung der Adenylatzyklase zum Anstieg des intrazellulären zyklischen Adenosinmonophosphats (cAMP), über weitere Schritte zu einem Anstieg der zytoplasmatischen Kalziumionenkonzentration und damit schließlich zur positiv-inotropen Wirkung. Stimulatorische $\left(G_{s}\right)$ und inhibitorische $\left(\mathrm{G}_{\mathrm{i}}\right)$ Guaninnukleotid-bindende Proteine (G-Proteine) regulieren diese rezeptorvermittelte Adenylatzyklasestimulation. Dieses System wird therapeutisch nicht nur beim Einsatz von Katecholaminen, sondern auch bei der Behandlung mit Phosphodiesterasehemmern genutzt.

Bei übermäßiger Stimulation der Adenylatzyklase durch endogene oder exogene Katecholamine, aber auch durch Phosphodiesterasehemmer, kommt es zur Abschwächung der inotropen Katecholaminwirkung am Herzen, hervorgerufen im wesentlichen durch eine Abnahme der Zahl der $\beta_{1}$-Adrenozeptoren auf der 


\section{MYOKARD}

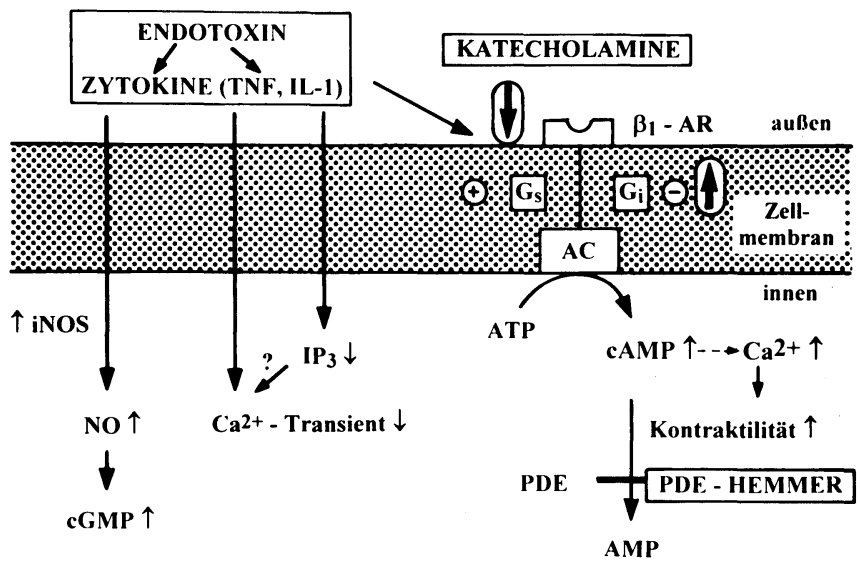

GEFÄSSE

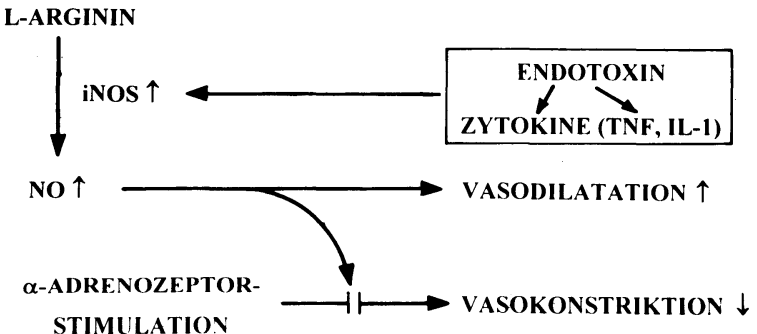

Abb. 11.7. Abschwächung der Katecholaminwirkung an Herz und Gefäßen in der Sepsis. $T N F$ Tumornekrosefaktor $\alpha ; I L-1$ Interleukin $1 ; I P_{3}$ Inositoltriphosphat; $i N O S$ induzierbare Stickoxidsynthase; NO Stickoxid. Weitere Erläuterungen s. Text und [21].

Herzmuskelzellmembran und in geringerem Maße auch durch eine Zunahme der $\mathrm{G}_{\mathrm{i}}$-Proteine. Mit diesen Desensibilisierungsmechanismen versucht die Herzmuskelzelle sich vor einer übermäßigen, deletären Katecholaminaktivierung - im Sinne einer katecholamininduzierten Herzschädigung - zu schützen, unter Inkaufnahme einer Abschwächung der positiv-inotropen Katecholaminwirkung. Durch Züchtung von Kardiomyozyten in Medium mit hohen Katecholaminkonzentrationen können diese Desensibilisierungsmechanismen auf zellulärer Ebene untersucht werden (Überblick in [21,39]): die Wirkungsabschwächung tritt innerhalb von Minuten bis Stunden ein, und sie ist nach Auswaschen des Katecholamins aus dem Züchtungsmedium innerhalb von $24 \mathrm{~h}$ reversibel.

Eine Abnahme der myokardialen $\beta_{1}$-Adrenozeptoren wird bei allen Formen der höhergradigen Herzinsuffizienz gefunden, hervorgerufen durch die hohen extrazellulären Katecholaminspiegel. Auch bei Patienten mit Sepsis finden sich ca. 10fach erhöhte Plasma-Noradrenalinspiegel und eine Abschwächung der 
positiv-inotropen Katecholamin-Wirkung (Literatur in $[21,37,57])$. Demzufolge kann auch bei der akuten septischen Kardiomyopathie die Abnahme der myokardialen $\beta_{1}$-Adrenozeptoren und die daraus resultierende Abschwächung der positiv-inotropen Wirkung endogener Katecholamine als eine der Ursachen der eingeschränkten Herzfunktion angenommen werden (Diskussion in $[21,39,56$, 57]).

Beim therapeutischen Einsatz von Katecholaminen läßt sich bei herzinsuffizienten Patienten erwartungsgemäß innerhalb weniger Tage eine Abschwächung der Wirkung bis hin zum völligen Wirkungsverlust nachweisen. Auch bei Patienten mit septischem Schock und akuter septischer Kardiomyopathie unterstützen kasuistische Beobachtungen den klinischen Eindruck, daß die durch Gabe von Katecholaminen erreichbare positiv-inotrope Wirkung durch eine zunehmende Katecholamintoleranzentwicklung abgeschwächt wird bzw. mit zunehmender Behandlungsdauer durch eine Steigerung der Katecholamindosierung kompensiert werden muß (Tabelle 11.4): die initial durch Noradrenalin erzielbare Zunahme des linksventrikulären Schlagarbeitsindex bei 6 Patienten mit septischem Schock konnte in den folgenden Tagen nur durch eine Verdoppelung der Noradrenalindosis aufrechterhalten werden. Die verwendeten Noradrenalindosierungen mit einem Austieg der Plasma-Noradrenalinkonzentration um das 1,4- bis 19fache [39, 40] - können dabei durchaus zur Katecholamindesensibilisierung des Herzens führen: die entsprechenden Patientenseren rufen in Rattenherzmukelzellkulturen innerhalb von $48 \mathrm{~h}$ eine $\beta$-Adrenozeptor-Downregulation um ca. $35 \%$ und eine damit verbundene Hemmung der Adenylatzyklaseaktivität um ca. 50\% hervor (Tabelle 11.4). Das Plasma septischer Patienten enthält demzufolge keine längerlebigen Toxine oder Mediatoren, die diese Katecholaminwirkungsabschwächung beeinflussen.

Da diese $\beta_{1}$-Adrenozeptor-Adenylatzyklase-Desensibilisierung jedoch alle am myokardialen $\beta_{1}$-Adrenozeptor angreifenden Katecholamine in gleichem Maß betrifft, resultieren daraus keine differentialtherapeutischen Konsequenzen.

Bei chronischer Herzinsuffizienz wird derzeit in kontrollierten Studien versucht, durch $\beta$-Blocker in sehr niedriger Dosierung die downregulierten myokardialen $\beta$-Adrenozeptoren wieder hochzuregulieren und damit die Katecholaminansprechbarkeit wieder zu verbessern. Bei Patienten mit akuter septischer Kardiomyopathie, bei denen ebenfalls von einer Katecholamindesensibilisierung ausgegangen werden muß, liegen bisher keine entsprechenden Erfahrungen vor.

Die myokardialen $\boldsymbol{\beta}_{2}$-Adrenozeptoren erfahren bei herzinsuffizienten Patienten keine Abnahme, trotzdem ist die Ansprechbarkeit auf $\boldsymbol{\beta}_{2}$-Sympathomimetika reduziert. $\alpha_{1}$-Adrenozeptoren stellen im menschlichen Herzen nur etwa $15 \%$ der Gesamtpopulation aller Adrenozeptoren; ob durch ihre Stimulation ein relevanter positiv-inotroper Effekt zu erzielen ist, wird kontrovers diskutiert. Bei höhergradiger Herzinsuffizienz bleibt die Zahl myokardialer $\alpha_{1}$-Adrenozeptoren unverändert bzw. nimmt sogar zu. Dennoch ist die positiv-inotrope Wirkung von $\alpha$-Adrenozeptoragonisten bei terminaler Herzinsuffizienz ebenfalls reduziert.

Neben der Katecholamindesensibilisierung tragen auch noch Toxin- und Mediator-verursachte Alterationen der Inotropiesignaltransduktionswege zur 
Tabelle 11.4. Katecholamintoleranzentwicklung ( $\bar{x} \pm S D)$ unter Noradrenalintherapie bei Patienten mit septischem Schock ${ }^{\mathrm{a}}$

\begin{tabular}{|c|c|c|c|c|c|}
\hline & Tag 0 & Tag 1 & Tag 2 & Tag 3 & Tag 4 \\
\hline Patientenzahl & 6 & 6 & 6 & 6 & 6 \\
\hline \multicolumn{6}{|l|}{ Dosierungen $(\mu \mathrm{g} / \mathrm{min})$ : } \\
\hline Noradrenalin & 0 & $7,4 \pm 37$ & $14,0 \pm 8,6$ & $13,2 \pm 7,0$ & $13,8 \pm 7,8$ \\
\hline Adrenalin & $3,3 \pm 4,7$ & 0 & $5,0 \pm 4,2$ & $11,0 \pm 12,5$ & $4,3 \pm 4,4$ \\
\hline Dopamin & $533 \pm 499$ & $200 \pm 0$ & $200 \pm 0$ & $200 \pm 0$ & $200 \pm 0$ \\
\hline \multicolumn{6}{|l|}{ Herz-Kreislauf-Parameter: } \\
\hline Herzindex $\left(1 / \mathrm{min} \cdot \mathrm{m}^{2}\right)$ & $3,3 \pm 1,0$ & $3,7 \pm 0,9$ & $3,6 \pm 1,0$ & $3,9 \pm 1,8$ & $3,9 \pm 1,2$ \\
\hline Arterieller Mitteldruck & & & & & \\
\hline$(\mathrm{mmHg})$ & $54 \pm 9$ & $70 \pm 8$ & $68 \pm 16$ & $65 \pm 5$ & $67 \pm 8$ \\
\hline \multicolumn{6}{|l|}{ Systemischer Gefäßwiderstand } \\
\hline $\begin{array}{l}\left(\text { dyn } \cdot \mathrm{s} \cdot \mathrm{cm}^{-5}\right) \\
\text { Linksventrikulärer }\end{array}$ & $540 \pm 198$ & $634 \pm 199$ & $634 \pm 254$ & $578 \pm 255$ & $556 \pm 188$ \\
\hline Schlagarbeitsindex $\left(\mathrm{g} \cdot \mathrm{m} / \mathrm{m}^{2}\right)$ & $25 \pm 11$ & $34 \pm 11$ & $32 \pm 7$ & $35 \pm 13$ & $36 \pm 9$ \\
\hline \multicolumn{6}{|c|}{$\begin{array}{l}\text { Katecholamindesensibilisierung von Rattenherzmuskelzellen durch Serum (1:1) der oben } \\
\text { charakterisierten Patienten ( } 48 \text {-h-Inkubation): }\end{array}$} \\
\hline$\beta_{1}$-Adrenozeptoren & $100 \%$ & $64 \pm 17$ & & & \\
\hline Adenylatzyklaseaktivität & $100 \%$ & $50 \pm 31$ & & & \\
\hline
\end{tabular}

a Bei 6 Patienten mit septischem Schock (davon 5 mit kardialen Vorerkrankungen) wurde eine Infusionsbehandlung mit Noradrenalin begonnen und die Auswirkungen auf Herzund Kreislaufparameter gemessen. Alle Patienten erhielten zusätzlich Dopamin in der angegebenen Dosierung; Adrenalin wurde zusätzlich an Tag 0 - 2 Patienten -, an Tag 2 4 Patienten - und an den Tagen 3 und 4 - 3 Patienten - gegeben.

a) Zur Aufrechterhaltung der hämodynamischen Besserung ist eine Verdoppelung der Noradrenalindosierung notwendig.

b) Das noradrenalinhaltige Patientenserum führt in kultivierten Rattenherzmuskelzellen zur Desensibilisierung des $\beta_{1}$-Adrenozeptor-Adenylatzyklase-Systems: Spontan kontrahierende neonatale Rattenherzmuskelzellen wurden für $48 \mathrm{~h}$ mit noradrenalinfreiem (Tag 0 ) und noradrenalinhaltigem Patientenserum - 1:1 verdünnt - inkubiert. Danach wurde mit Membranpräparationen die Zahl der $\beta_{1}$-Adrenozeptoren mittels Bindung des Radioliganden $\left({ }^{3} \mathrm{H}\right)$ CGP $12177(2 \mathrm{nM})$ und die Isoproterenol $(100 \mu \mathrm{M})$-stimulierte Adenylatzyklaseaktivität im Vergleich zu Kontrollzellen ermittelt, welche zusätzlich mit dem $\beta$-Blocker Timolol $(0,1 \mu \mathrm{M})$ inkubiert worden waren. (Nach [39])

Abschwächung der Katecholamintherapie bei (ausführliche Diskussion in [21, 55]).

Zusammengenommen resultiert daraus ein sehr komplexes Bild der verminderten Wirksamkeit von Katecholaminen in der Sepsis: Tatsache ist, daß bei Patienten mit septischem Schock Katecholamine - Dobutamin - eine geringere positiv-inotrope Wirkung hervorrufen als bei Patienten mit Sepsis, aber ohne Schock [44]. Diese Katecholamintoleranz ist zumindest partiell auf eine Dysregulation des $\beta$-Adrenozeptor-Adenylatzyklase-Systems zurückzuführen, hervor- 
gerufen durch endogene und pharmakologisch applizierte Katecholamine, sowie durch Zytokine und andere Sepsismediatoren (Abb. 11.7; Tabelle 11.4, [21, 39, 44, $55,57)$. Sie sollte eigentlich die Wirkung aller Katecholamine, die ihre positivinotrope Wirkung durch Besetzung und Stimulation der myokardialen $\beta_{1^{-}}$ Adrenozeptoren entfalten, in quantitativ gleicher Weise betreffen. Dennoch gibt es klinische und experimentelle Befunde, die von diesem Konzept anscheinend abweichen: Nur bei der Infusionsbehandlung mit Noradrenalin, nicht aber bei der mit Dopamin, war bei einer kleinen Patientengruppe mit septischem Schock eine Dosiserhöhung zur anhaltenden hamodynamischen Stabilisierung notwendig [39]. In Hunden mit E.-coli-Sepsis trat für das Noradrenalin eine Abschwächung seiner positiv-inotropen Wirkung ein, während die des Dopamins erhalten blieb; das umgekehrte war jedoch bzgl. der blutdrucksteigernden Gefäßwirkung der Fall, mit einer wesentlichen besser konservierten Wirkung des Noradrenalins als der des Dopamins in der Sepsis [15]. Die günstige Wirkung der Volumensubstitution auf die Herzfunktion (Zunahme des Schlagvolumenindex, des Herzindex und der Auswurffraktion) ließ sich in diesen Untersuchungen nur in Abwesenheit von Katecholaminen nachweisen [15]. Differentialtherapeutische Konsequenzen für die Klinik sind aus diesen Ergebnissen jedoch noch nicht abzuleiten.

Auch die Gefäße zeigen im septischen Schock eine Katecholamintoleranz, mit einer abgeschwächten bis fehlenden Vasokonstriktion auf $\alpha$-Adrenozeptoragonisten. In diesem Falle scheint jedoch nicht die im Tierexperiment bei Sepsis und Endotoxinämie gefundene Abnahme der Zahl der Gefäß- $\alpha$-Adrenozeptoren die entscheidende Rolle $\mathrm{zu}$ spielen, sondern vielmehr das vermehrt gebildete Stickoxid: durch Hemmstoffe der Stickoxidsynthese läßt sich im Sepsis- und Endotoxintiermodell die stark abgeschwächte vasokonstriktorische Katecholaminwirkung wieder restaurieren (Abb. 11.7; [27], S. 94-103 und S. 104-118). Die Zahl der Gefäß- $\boldsymbol{\beta}_{2}$-Adrenozeptoren ist im Tierexperiment bei Sepsis und Endotoxinämie als nicht verändert beschrieben.

\section{Differentialtherapie mit Katecholaminen}

bei akuter septischer Kardiomyopathie und septischem Schock

Im Gegensatz zum kardiogenen Schock, bei dem die Einschränkung der Pumpleistung des Herzens ganz im Vordergrund steht, mit kompensatorischer Zunahme des systemischen Gefäßwiderstands, dominiert beim septischen Schock primär die toxin- und mediatorbedingte Kreislaufschädigung mit zunehmender Vasodilatation das klinische Bild; bereits in einem frühen - noch normotensiven - Stadium kann es aber auch zur ausgeprägten, behandlungspflichtigen Myokarddepression im Sinne der akuten septischen Kardiomyopathie kommen [12].

Der erniedrigte Gefäßwiderstand infolge Vasodilatation beim septischen Schock spricht dafür, bei einem notwendig werdenden Einsatz (Abb. 11.8) primär Katecholamine mit vasokonstriktorischer Komponente - Dopamin, Noradrenalin - zu verwenden [56], um einen mittleren Blutdruck von mindestens $60 \mathrm{~mm} \mathrm{Hg}$ aufrechtzuerhalten [26]. Andererseits können auch mit Katecholaminen ohne 


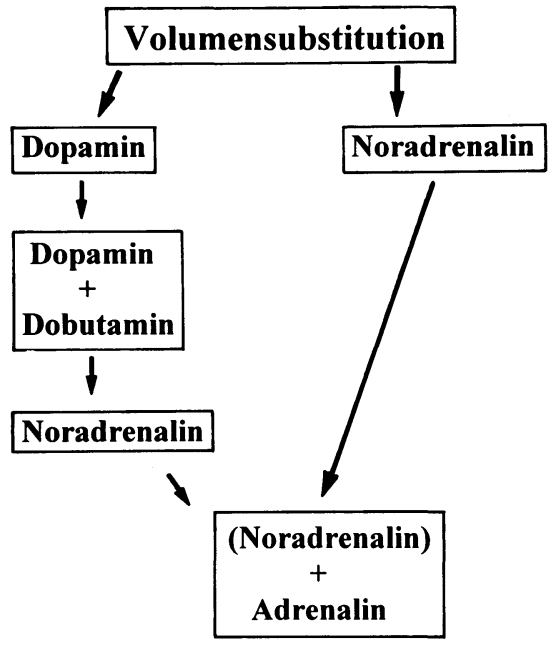

Abb. 11.8. Differentialtherapie mit Katecholaminen bei akuter septischer Kardiomyopathie und septischem Schock. (Erläuterungen s. Text. Das Schema spiegelt das aktuelle Konzept des Autors wider; s. dazu auch [4]; [24], S. 1584-1594; [26], [37], S. 137-152 und 414-423; [38, 40]; [51], S. 186-196; Kap. 10)

vasokonstriktorische Komponente - Dobutamin - günstige Ergebnisse erzielt werden, z. B. bei im Vordergrund stehender septischer Kardiomyopathie. Durch die Kombination unterschiedlicher Katecholamine (Abb. 11.8) läßt sich nicht selten therapeutisch mehr erreichen als mit Einzelsubstanzen allein ([4]; [37], S. 414-422; [56]). Selbst bei ausgeprägter Vasodilatation sollte ein reiner $\alpha-$ Adrenozeptoragonist - wie z. B. das Phenylephrin - nicht eingesetzt werden, da er durch die Nachlasterhöhung den Herzindex reduziert, ohne die Gewebeperfusion und die $\mathrm{O}_{2}$-Verfügbarkeit im Gewebe zu verbessern ([4]; s. dazu aber [37] S. 414-423).

Katecholamine mit vasokonstriktorischer Komponente haben Vor- und Nachteile. Die bessere Aufrechterhaltung der Gewebeperfusion und die Blutumverteilung aus dem Haut- und Muskelgewebe in die Vitalorgane sind zumindest theoretisch Vorteile der katecholaminbedingten Vasokonstriktion. Potentielle Nachteile spielen v. a. beim septischen Schock keine große Rolle: die Nachlasterhöhung ist in der Regel nicht sehr ausgeprägt, da der Gefäßwiderstand nur selten auf Normalwerte angehoben werden kann. Auch die nachlastbedingte Steigerung des myokardialen $\mathrm{O}_{2}$-Verbrauchs dürfte sich bei dieser Schockform nicht sehr nachteilig auswirken, da die septische Herzschädigung zwar eine Myokarddepression mit erhöhter Ventrikelcompliance beinhaltet, die Koronargefäße jedoch dabei nicht konstringiert, sondern weitgestellt sind ([27], S. 89-93). Die vasokonstriktorische Katecholaminkomponente kann einen intravasalen Volumenmangel maskieren; eine adäquate Flüssigkeitsgabe ist deshalb vor Einsatz vasopressorischer Katecholamine besonders wichtig.

Bedingt durch die toxin- und mediatorbedingte Schädigung von Herz und Gefäßen und durch die oben beschriebenen Katecholamindesensibilisierungsmechanismen sind häufig höhere Katecholamindosen als in Tabelle 11.3 angegeben erforderlich, um überhaupt noch eine positiv-inotrope bzw. vasokonstriktorische Wirkung bei diesen Patienten zu erzielen. 
Wie bereits ausgeführt (s. Abschn. „Dopamin in „Nierendosis“: Protektive Wirkung bisher nicht belegt“ S. 222), ist der häufig praktizierte Einsatz von niedrigdosiertem Dopamin („Nierendosis“) zur Nephroprotektion in seiner Wirksamkeit nicht gesichert, aber potentiell nebenwirkungsbelastet. Er kann deshalb weder als Monotherapie noch in Kombination mit vasokonstriktorischen Katecholaminen wie Noradrenalin generell empfohlen werden [38, 42, 48]. Das Vorliegen einer Azidose führt $\mathrm{zu}$ einem verminderten Ansprechen des Herzens auf Katecholamine, allerdings erst ab pH $\leq 7,20$ ([51], S. 186-196).

Differentialtherapeutische Aspekte der Katecholamingabe im Hinblick auf eine Optimierung der Gewebeperfusion und des $\mathrm{O}_{2}$-Stoffwechsels im Gewebe werden in Kap. 10 ausführlich abgehandelt. Hier soll nur angefügt werden, daß mit Katecholaminen ohne wie auch mit vasokonstriktorischer Komponente $\mathrm{O}_{2}$ Angebot und $\mathrm{O}_{2}$-Verbrauch gesteigert werden konnten. Sowohl bei postoperativ kritisch Kranken als auch bei septischen Patienten scheint eine günstige Prognose an einen relativ hohen $\mathrm{O}_{2}$-Transport ( $>600 \mathrm{bzw}$. $800-1000 \mathrm{ml} / \mathrm{min} / \mathrm{m}^{2}$ ) und $\mathrm{O}_{2}$ Verbrauch (> 170 bzw. $180 \mathrm{ml} / \mathrm{min} / \mathrm{m}^{2}$ ) geknüpft zu sein (Zitat 46 in [56]).

Der Nutzen dieser supranormalen $\mathrm{O}_{2}$-Versorgung ist iedoch in Frage gestellt (s. Abschn. „Katecholamine und supranormales $\mathrm{O}_{2}$-Augebot: mit mehr Sauerstoff allein ist es nicht getan“, S. 223).

\section{Weitere positiv-inotrope und vasoaktive Pharmaka}

\section{Phosphodiesterasehemmstoffe (weiterführende Literatur in [38])}

Von den Alternativen zu den im wesentlichen bei Patienten mit Sepsis zum Einsatz gelangenden Katecholaminen Dobutamin, Dopamin, Noradrenalin und Adrenalin ist v. a. die Gruppe der positiv-inotrop und vasodilatierend wirkenden Phosphodiesterasehemmer (z. B. Amrinon, Milrinon, Enoximon) zu nennen. Durch Hemmung des Abbaus des cAMP (Abb. 11.7) bewirken sie über einen zusätzlichen, von der $\beta$-Adrenozeptorstimulation unabhängigen Wirkmechanismus einen weiteren Anstieg des zellulären cAMP, was im Herzen einen positivinotropen und in den Gefäßen einen vasodilatierenden Effekt zur Folge hat. Auch mit diesen Substanzen kann eine Verbesserung des $\mathrm{O}_{2}$-Metabolismus erzielt werden (Zitat 24 in [56]). Im Tiermodell (Schweine) des septischen Schocks ließ sich mit dem Phosphodiesterasehemmer Milrinon - ohne zusätzliche Katecholamingabe - zwar das Herzzeitvolumen länger im Normbereich halten, es kam jedoch $\mathrm{zu}$ einem stärkeren Blutdruckabfall, die pulmonale Hypertonie wurde nicht wesentlich gesenkt, und die Prognose der Tiere wurde durch Milrinon nicht gebessert, sondern eher verschlimmert. Die schlechte Steuerbarkeit (Halbwertszeit des Enoximons bei herzinsuffizienten Patienten: 3-20 h) und eine ausgeprägte Vasodilatation müssen als mögliche Probleme beim Einsatz dieser Substanzen berücksichtigt werden und schränken ihre Anwendung gerade beim septischen Schock doch erheblich ein.

Bei der Kombination eines Katecholamins mit einem Phosphodiesterasehemmer erwartet man sich eine stärkere positiv-inotrope Wirkung als bei der jeweili- 
gen Monotherapie. Bei vorbestehender Vasodilatation (septischer Schock) sollte dann aber eher ein vasokonstriktorisches Katecholamin zum Einsatz gelangen: So wurde über eine günstige Wirkung der Kombination eines Phosphodiesterasehemmers mit Noradrenalin berichtet, mit einer additiven positiv-inotropen Wirkung ohne Verstärkung der Vasodilatation ([51], S. 186-196).

Aufgrund der potentiell schwer traktablen Nebenwirkungen und der schlechten Steuerbarkeit bei nicht klar belegter Prognoseverbesserung zählen Phosphodiesterasehemmer derzeit nicht zur Standardtherapie des septischen Schocks. Ihr Einsatz sollte allenfalls beschränkt werden auf Patienten mit einer hypodynamen behandlungsrefraktären Form des septischen Schocks, mit stark eingeschränkter Herzfunktion und einem eher hohen systemischen Gefäßwiderstand. Auf eine adäquate vorherige Volumensubstitution ist besonderer Wert zu legen.

\section{Angiotensin II}

Im katecholaminrefraktären septischen Schock sind günstige hämodynamische Wirkungen des Angiotensin II (5-20 $\mu \mathrm{g} / \mathrm{min})$ beschrieben worden [47]. Der durch Angiotensin II erzielbare Anstieg des Blutdrucks kann aber mit einer deutlichen Einschränkung des Herzindex einhergehen [4]. Deshalb sollten vor Einleiten der Angiotensinbehandlung die Möglichkeiten der Noradrenalintherapie (vasokonstriktorische bei gleichzeitig positiv-inotroper Wirkung) ausgeschöpft werden.

\section{Vasodilatatoren (weiterführende Literatur in [38])}

Eine Vasodilatatorentherapie mit Nitroglyzerin- oder Natriumnitroprussidinfusionen ist auf die wenigen Patienten mit hypodynamem septischen Schock trotz adäquater Volumenzufuhr beschränkt, die einen erhöhten systemischen Gefäßwiderstand und einen hohen Pulmonalkapillardruck aufweisen. Darüber hinaus erscheint ein Behandlungsversuch bei Patienten gerechtfertigt, die - bei normalem oder erhöhtem Blutdruck - eine Funktionseinschränkung vitaler Organe infolge Minderperfusion aufweisen. Hier kann durch den Einsatz von Vasodilatatoren versucht werden, die erwünschte Umverteilung der Durchblutung zu erreichen die sich als Besserung der Organfunktion manifestieren sollte [26]. Kontrovers diskutierte Behandlungsversuche mit den Prostaglandinderivaten PG $E_{1}$ und PG $I_{2}$ ([24], S. 1587) betreffen v. a Patienten mit ARDS.

\section{N-Azetylzystein}

$\mathrm{N}$-Azetylzystein fungiert als Antioxidans und SH-Gruppendonator, es hemmt die Granulozytenaggregation und vermindert die Permeabilitätsstörung der Mikrozirkulation. Bei Hunden mit Endotoxinschock wurde mit N-Azetylzystein eine Steigerung des reduzierten Herzindex und des linksventrikulären Schlagar- 
beitsindex erzielt; bei Patienten mit septischem Schock ließ sich damit eine Anhebung des Herzindex erreichen. Generelle Empfehlungen zum Einsatz von NAzetylzystein bei Sepsis und septischem Schock können daraus jedoch noch nicht abgeleitet werden (ausführliche Diskussion in [38]).

\section{Glukagon}

Glukagon wirkt über eine glukagonrezeptorvermittelte Stimulation der Adenylatzyklase am Herzen positiv-inotrop und -chronotrop. Sein Einsatz (1-4-6 mg i. v., danach eine Infusion mit $2-10 \mathrm{mg} / \mathrm{h}$ ) wird eigentlich nur noch empfohlen bei mit $\beta$-Blockern behandelten Patienten mit Hypotonie, bei denen die konventionelle Therapie fehlgeschlagen ist ([4]; [37], S. 414-423; [51], S. 186-196).

\section{Kalzium}

Unter Umgehung desensibilisierter bzw. geschädigter Adrenozeptoren kann über einen sehr beschränkten Zeitraum durch Kalziuminfusionen $(20 \mathrm{mmol} / \mathrm{h}$; [7] ein septischer Schockzustand gebessert werden ([7]; [51], S. 186-196), unter Ausnutzung sowohl der positiv-inotropen als auch der vasokonstriktorischen Kalziumwirkung. Ein Anstieg des ionisierten Serumkalziums limitiert in der Regel dieses Vorgehen nach Stunden [7]. Möglicherweise könnten auch Kalziumagonisten (z. B. Bay K 8644) eine günstige Wirkung im septischen Schock zeigen ([51], S. 186-196); ausreichende klinische Erfahrungen liegen dazu aber nicht vor.

In diesem Zusammenhang erscheint es erwähnenswert, daß die negativinotrope und -chronotrope Wirkung eines im Schock mit erhöhter Aktivität gefundenen, als Peptid identifizierten kardiodepressiven Faktors (CDF) auf eine Blockade des Kalziumeinstroms in die Herzmuskelzelle zurückgeführt werden kann $[21,57]$.

\section{Digitalis}

Die Wirksamkeit von Digitalis im septischen Schock als positiv-inotropes Agens wurde von Vincent ([51], S. 186-196) als enttäuschend eingestuft. Wie bei anderen Formen der akuten Herzinsuffizienz sind Katecholamine auch im septischen Schock die Inotropika der ersten Wahl, während die Wirkung von Digitalis als bestenfalls geringgradig $\mathrm{zu}$ klassifizieren ist. In Abwägung des geringen Nutzens und der erschwerten Steuerbarkeit durch Elektrolytstörungen und Nierenfunktionseinschränkungen in der Sepsis sollte die Indikation zur Digitalisierung bei diesen Patienten sehr streng gestellt werden: eine klare Indikation ist nach Ansicht des Autors nur noch bei bestimmten Rhythmusstörungen (z. B. tachykardes Vorhofflimmern, Vorhofflattern) gegeben, unter sorgfältiger Überwachung und Dosisanpassung. 
Diuretika, Hämofiltration und Hämodialyse

Die Behandlung des prärenalen Nierenversagens bei septischem Schock mit Diuretika (Furosemid, Etacrynsäure), Hämofiltration oder Hämodialyse unterscheidet sich nicht von der Behandlung eines akuten Nierenversagens nichtseptischer Genese (s. dazu auch S. 208-209 und Kap. 9.)

\section{Rhythmusmonitoring und antiarrhythmische Therapie}

Ein spezifisches Muster an Rhythmusstörungen ist für die akute septische Kardiomyopathie nicht dokumentiert. Dennoch muß mit potentiell malignen Rhythmusstörungen gerechnet werden, wozu Elektrolytentgleisungen, akutes Nierenversagen, Hypo- und Hypervolämie, Katecholamintherapie, kardiale Vorekrankungen und Fieber beitragen. Ein Patient mit Sepsis und Multiorganversagen sollte kontinuierlich EKG-monitorüberwacht werden. Bei Auftreten von Rhythmusstörungen unterscheidet sich die antiarrhythmische und Defibrillatortherapie nicht grundlegend von der bei nichtseptischen Patienten. Obwohl dem Adrenalin die größte arrhythmogene Wirkung unter den zum Einsatz gelangenden Katecholaminen zugeschrieben wird, können Rhythmusstörungen grundsätzlich unter jedem Katecholamin dosisabhängig aufreten und ein empirisches Umsetzen erforderlich machen.

\section{Oxygenierung, Beatmung und Reduktion der Herzarbeit}

Hypoxämie und eine übermäßige Atemarbeit können zur Verschlimmerung der Herzinsuffizienz beitragen. Die Ausschaltung der Hypoxämie läßt sich durch Wahl der geeigneten Atemunterstützung bzw. Beatmungsform erreichen (s. Kap. 12); eine gemessene arterielle $\mathrm{O}_{2}$-Sättigung von mindestens $90 \%$ und ein arterieller $\mathrm{O}_{2}$-Partialdruck von mindestens $60 \mathrm{~mm} \mathrm{Hg}$ können als Kontrollparameter herangezogen werden [4]. Die aktive Atemarbeit ist am gesamten $\mathrm{O}_{2}$-Verbrauch mit einem hohen Anteil beteiligt; bei bestimmten Lungen-Thorax-Traumata und Multiorganversagen kann dieser bis zu 50\% betragen [4]. Bereits bei den ersten Hinweisen auf eine erhöhte Atemarbeit (Tachypnoe mit vermindertem Atemzugvolumen und Hyperventilation) sollte eine entsprechende Atemunterstützung vorgenommen werden (s. Kap. 12], um bei akuter septischer Kardiomyopathie zur Entlastung des Herzens beizutragen. Dazu dienen auch Anxiolyse und Analgesie, Relaxierung zur Einsparung von Sedativa (s. unten) und die Beseitigung von Fieber ([20]; Hyperthermie steigert den $\mathrm{O}_{2}$-Verbrauch um $7 \%$ pro ${ }^{\circ} \mathrm{C}[4]$ ). Ebenfalls beachtet werden müssen die negativen Auswirkungen der PEEP-Beatmung auf die Herzfunktion (Zunahme der rechtsventrikulären Nachlast, Zunahme des rechtsventrikulären Durchmessers und Abnahme der linksventrikulären diastolischen Dehnbarkeit, direkte myokarddepressive Wirkung), ebenso bei CMV und IMV [4]. 
Die Myokarddepression der akuten septischen Kardiomyopathie kann weiterhin verstärkt werden durch Anästhetika und Barbiturate. Während Benzodiazepine und Opiate für sich keine relevante Myokarddepression hervorrufen - mit Ausnahme von Meperiden - können sie in Kombination einen additiven negativinotropen Effekt induzieren [4].

\section{Kausale Therapie der akuten septischen Kardiomyopathie}

Bei der akuten septischen Kardiomyopathie muß von einer multifaktoriellen Genese ausgegangen werden; dabei ist der jeweilige Stellenwert der einzelnen Bakterientoxine und Sepsismediatoren noch weitgehend ungeklärt (Abb. 11.9; $[21,55,57])$. Ähnliches muß auch von der Gefäßschädigung in der Sepsis angenommen werden. Hier wird derzeit v.a. dem vasodilatierend wirkenden Stickoxid (NO) ein hoher Stellenwert eingeräumt.

Die kausale Therapie der akuten septischen Kardiomyopathie und der Vasodilatation steckt noch in den Anfängen [55]; sie hat zum Ziel, die zur Herzfunktionseinschränkung und Vasodilatation führende Sepsisschädigungskaskade zu unterbrechen, und zwar durch Neutralisierung, Antagonisierung und Eliminierung der involvierten Bakterientoxine und Sepsismediatoren. Über den Stellen-

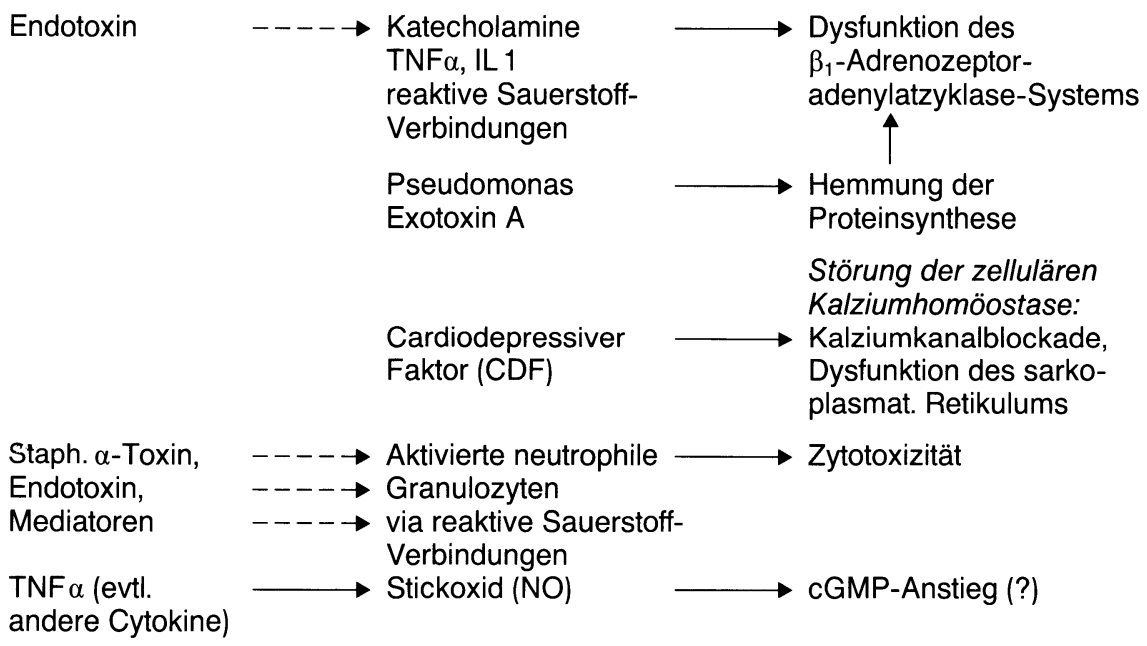

\footnotetext{
Abb. 11.9. Nachgewiesene „negativ-inotrope Kaskaden“ in Kardiomyozyten, hervorgerufen durch Bakterientoxine und Sepsismediatoren. Das Schema faßt In-vitro-Daten aus Experimenten mit Kardiomyozyten zusammen. Die durchgezogenen Pfeile markieren belegte Reaktionswege; die unterbrochenen Pfeile weisen auf weitere mögliche negativinotrope Wirkungen von Bakterientoxinen und Sepsismediatoren hin, die diese durch Stimulation von Mediatorzellen (z.B. neutrophile Granulozyten) und konsekutiver Mediatorfreisetzung (z. B. von TNF $\alpha$ und IL-1) hervorrufen könnten (TNF $a$ Tumornekrosefaktor $\alpha$, Il 1 Interleukin 1; cGMP zuklisches Guanosinmonophosphat; NO Stickoxid; Staph Staphylokokken). (Ausfuhrliche Diskussion in $[21,55,57]$ )
} 
wert dieser Behandlungsversuche kann derzeit noch keine gesicherte Aussage gemacht werden.

\section{Endotoxinantikörper}

Auf den therapeutischen Einsatz des Endotoxinantikörpers HA-1A (Centoxin) bei gramnegativer Sepsis waren große Hoffnungen gesetzt worden, die sich jedoch nicht erfüllten; der Antikörper ist zwischenzeitlich aus dem Handel gezogen (s. Kap. 6).

Auch die septische Kardiomyopathie scheint er nicht günstig zu beeinflussen: in Form kasuistischer Beobachtungen bei 6 Patienten mit vermuteter gramnegativer Sepsis (nur in einem Fall mit dokumentierter gramnegativer Bakteriämie) sahen wir nach Gabe von 100 mg Centoxin ${ }^{\mathrm{R}}$ i.v. innerhalb von 4 Tagen keinen Anstieg des erniedrigten linksventrikulären Schlagarbeitsindex (Tabelle 11.5).

Tierexperimentell verursacht dieser Endotoxinantikörper sogar eine Verschlechterung der Herz-Kreislauffunktion [32]: bei E. coli-Sepsis in Hunden führt die Applikation des HA-1A-Antikörpers $(10 \mathrm{mg} / \mathrm{kg}$ ) im Vergleich zu Placebo zu einer weiteren Abnahme des erniedrigten mittleren Blutdrucks (von 108 auf $88 \mathrm{~mm} \mathrm{Hg}$ ), verbunden mit einer Reduktion des Herzindex von 251 auf 146 $\mathrm{ml} / \mathrm{kg} \cdot \mathrm{min}$ und des linksventrikulären Schlagarbeitsindex von 1,92 auf 0,96 $\mathrm{g} / \mathrm{m} \cdot \mathrm{kg}$. Auffallenderweise ist diese Herzfunktionseinschränkung mit einer Abnahme des linksventrikulär-enddiastolischen Volumens bei gleichbleibendem Füllungsdruck vergesellschaftet, was auf eine Compliance-Störung hinweist.

Diese ungünstigen Wirkungen werden auf die mangelnde Spezifität des HA1A-IgM-Antikörpers zurückgeführt: er bindet nicht nur an das Endotoxinmolekül, sondern auch an zahlreiche andere strukturverwandte Verbindungen, wie z. B. Cardiolipin und HD-Lipoproteine [32]. Deshalb dürfen die Negativergebnisse mit HA-1A nicht als repräsentativ für das „Prinzip Endotoxinneutralisierung" angesehen werden. Allerdings liegen derzeit keine Informationen über die Wirkung weiterer Endotoxinantikörper auf die septische Herz-KreislaufSchädigung vor.

\section{Tumornekrosefaktor $\alpha$-Antikörper (TNF $\alpha$-AK)}

TNF $\alpha$ wird als einer der wesentlichen Mediatoren der Gefäßschädigung in der Sepsis angesehen, und auch bei der akuten septischen Kardiomyopathie dürfte er ursächlich eine wesentliche Rolle spielen [6, 21, 53,55]. Placebokontrollierte Sepsistherapiestudien zur Frage einer möglichen Letalitätssenkung durch TNF $\alpha$ AK sind im Gang (s. Kap. 8). Nach einmaliger Gabe von TNF $\alpha$-AK sahen Vincent et al. [53] bei 10 Patienten innerhalb von $2 \mathrm{~h}$ einen Anstieg des linksventrikulären Schlagarbeitsindex um $19 \%$ (von $26,5 \pm 5,6$ auf $31,5 \pm 10,5 \mathrm{~g} \cdot \mathrm{m} / \mathrm{m}^{2}$ ) im Sinne einer Besserung der bestehenden akuten septischen Kardiomyopathie. Eigene kasuistische Beobachtungen an 20 Patienten mit septischem Schock, die über 


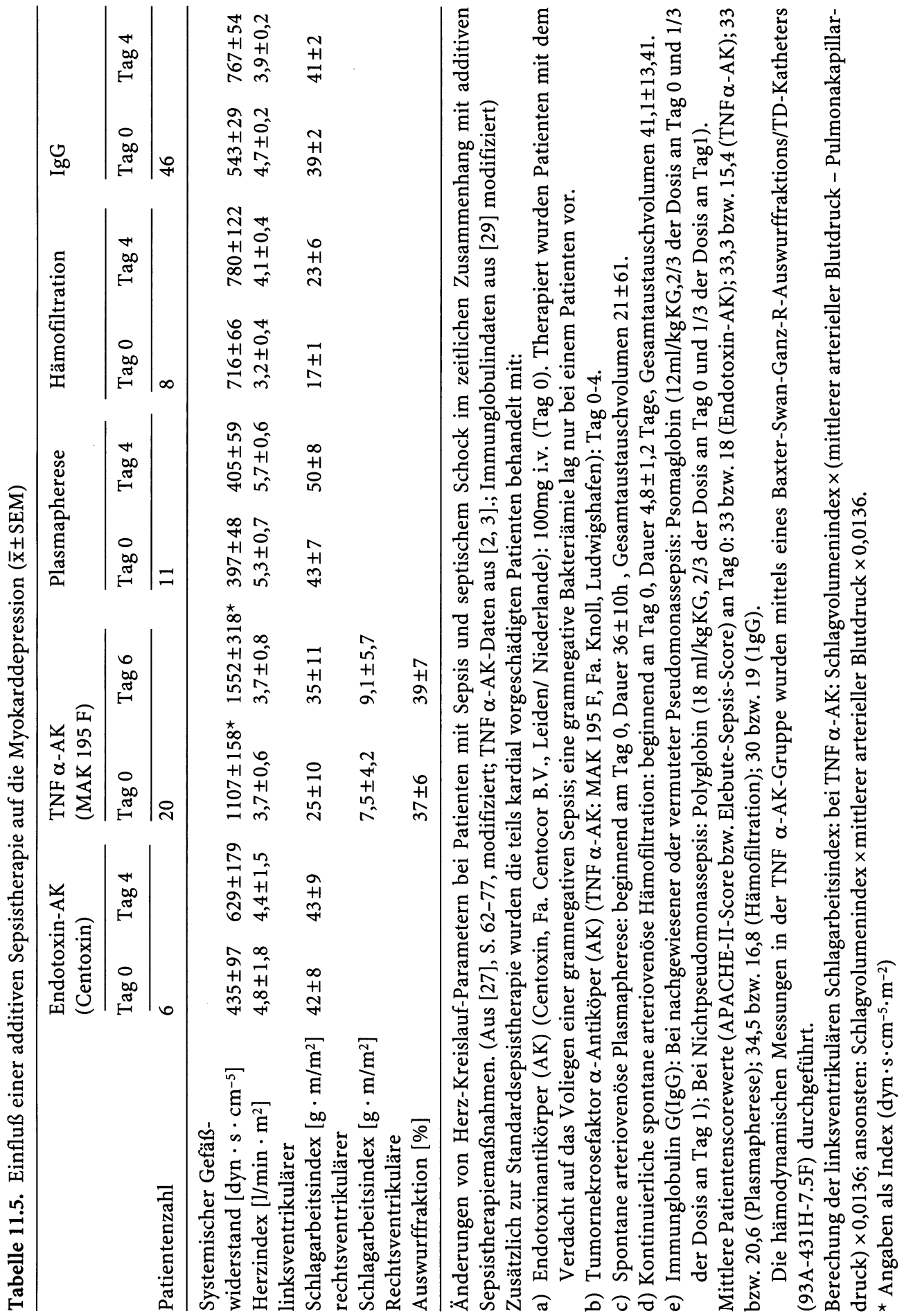


jeweils 5 Tage mit TNF $\alpha$-AK behandelt worden sind (TNF $\alpha$-AK MAK 195F, Fa. Knoll, Ludwigshafen), bestätigen diesen günstigen Trend, mit einem Austieg des LVSWI um $10 \mathrm{~g} \cdot \mathrm{m} \cdot \mathrm{m}^{-2}$ (Tabelle 11.5), zusätzlich zu der bei diesen Patienten bereits erzielten Katecholamininotropie [2,3]. Dieser eher gering anmutende LVSWI- Anstieg von $10 \mathrm{~g} \cdot \mathrm{m} \cdot \mathrm{m}^{-2}$ durch TNF $\alpha$-AK muß jedoch in Relation zu der durch Katecholamine erzielbaren LVSWI-Steigerung bei diesen Patienten gesehen werden: Tabelle 11.4 dokumentiert einen LVSWI-Anstieg durch Noradrenalin von ebenfalls nicht mehr als $11 \mathrm{~g} \cdot \mathrm{m} \cdot \mathrm{m}^{-2}$.

\section{Immunglobuline}

Der Stellenwert der Immunglobuline bei der Behandlung von Sepsis und septischem Schock wird ausführlich in Kap 6 diskutiert. An dieser Stelle sollen lediglich Aspekte zur Sprache kommen, die sich mit ihrem Einfluß auf die Herz-KreislaufSchädigung bei Sepsis und septischem Schock beziehen:

Bei 62 Patienten mit schwerer postoperativer Sepsis und einem Sepsisscore von $\geq 20$ führte die Gabe eines polyvalenten Immunglobulins $\mathrm{G}$ (Sandoglobulin; Sandoz, Basel/Schweiz; 0,4 g/kgKG an den Tagen 0,1 und 5 gegeben) zu einer Letalitätssenkung von $67 \%$ in der Placebo(Albumin)-Gruppe auf $38 \%$ in der Immunglobulin-G-Gruppe (s. Kap. 6: dort Zitat Dominioni et al. [18]). Der Rückgang der Sterblichkeit war dabei ausschließlich auf den Rückgang der Todesfälle infolge septischen Schocks von 33 auf $7 \%$ zurückzuführen. während der Anteil des Multiorganversagens als Todesursache durch die Immunglobulingabe nicht vermindert wurde (30 vs. $31 \%$ ). Die Befunde sprechen für eine günstige Beeinflussung der septisch bedingten Herz-Kreislauf-Schädigung durch Immunglobulin G.

In die gleiche Richtung weisen die Ergebnisse einer Fallbeobachtungsstudie, bei der Patienten mit Sepsis bzw. septischem Schock mit einem polyvalenten IgGPräparat (Polyglobin N; Troponwerke Biologische Präparate, Köln) bzw. - bei nachgewiesener oder vermuteter Pseudomonassepsis - mit einem Pseudomonasimmunglobulin (Psomaglobin, Troponwerke Biologische Präparate, Köln) behandelt worden sind (Dosierung und zeitlicher Ablauf s. Erläuterungen unter Tabelle 11.5). Wie der Tabelle $11.5 \mathrm{zu}$ entnehmen ist, kommt es dabei in engem zeitlichen Zusammenhang mit der Behandlung zu einem Anstieg des systemischen Gefäßwiderstands um ca. 220E. Analysiert man die „Gefäßantwort“ auf die Gabe von IgG, so fällt auf, daß etwa die Hälfte aller Patienten mit dem Gefäßwiderstand ansteigt (Abb. 11.10; „Responder“: $\geq 24 \mathrm{~h}$ anhaltender Anstieg des systemischen Gefäßwiderstands um mindestens $160 \mathrm{E}$ innerhalb von 4 Tagen nach Beginn der Immunglobulinbehandlung [29]), während die andere Hälfte der Patienten keine Besserung des erniedrigten Gefäßwiderstands zeigt („NonResponder"). Parallel zum Anstieg des systemischen Gefäßwiderstands fällt der Herzindex ab (Tabelle 11.5, Abb. 11.10). Dieser Abfall ist nicht als eine Zunahme der Herzschädigung unter Immunglobulingabe zu deuten, sondern er resultiert aus der inversen Abhängigkeit des Herzindex vom systemischen Gefäßwiderstand (s. Abb. 11.2 und Kap. 2: Abb. 2.5). 


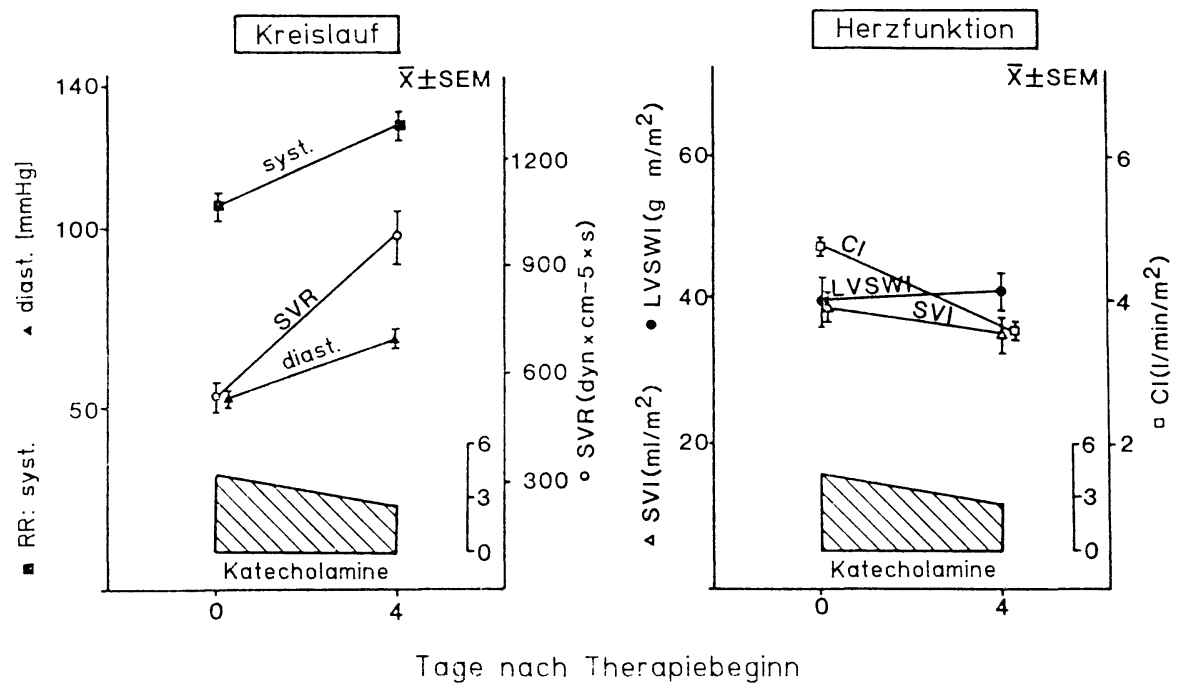

Abb. 11.10. Hämodynamische Änderungen bei Patienten mit septischem Schock in zeitlichem Zusammenhang mit einer additiven Immunglobulingabe. 46 Patienten mit unter Standardtherapie progredientem septischen Schock wurde zusätzlich an 2 Tagen (Tag 0 und 1 in der Abbildung) polyvalentes Immunglobulin G bzw. Pseudomonasimmunglobulin $\mathrm{G}$ gegeben [29]. Im zeitlichen Zusammenhang mit dieser Immunglobulingabe kam es bei 24 Patienten zu keiner wesentlichen Änderung des erniedrigten systemischen Gefäßwiderstands. Bei 22 Patienten - deren Daten in der Abbildung gezeigt sind - stieg der systemische Gefäßwiderstand (SVR) deutlich an (linke Abbildung) und trennte auf diese Weise „hämodynamische Responder“ (Anstieg des SVR $>160 \mathrm{dyn} \cdot \mathrm{cm}^{-5} \cdot \mathrm{s}$ ) mit besserer Prognose von den „hämodynamischen Non-Respondern“ [29]. Im Gegensatz zur Besserung der Kreislaufsituation konnte bei diesen Patienten keine Besserung der eingeschränkten Herzfunktion (SVI Schlagvolumenindex; LSWI linksventrikulärer Schlagarbeitsindex; CI Herzindex) gemessen werden. Der Abbildung liegen Daten aus [29] zugrunde.

Die hämodynamischen „Immunglobulinresponder“ haben eine signifikant bessere Prognose als die „Non-Responder“ (Letalitat $27 \%$ vs. $77 \%$ nach [29]), und die Besserung der Kreislauffunktion korreliert ebenso mit einer Besserung des Multiorganversagens, was sich anhand des Abfalles des APACHE-II-Scores bei diesen Patienten dokumentieren läßt [29]. Auch eine Abnahme des in der Sepsis erhöhten Skelettmuskel- $\mathrm{pO}_{2}$ durch Psomaglobin wurde beschrieben [1], ein Befund, der als eine Steigerung der gestörten $\mathrm{O}_{2}$-Verwertung im Skelettmuskel durch das Immunglobulin gedeutet werden könnte.

Die gleichen „Responder“, die auf die Gabe von IgG mit einem Anstieg des Gefäßwiderstands und des Blutdrucks reagieren (Abb. 11.10, Tabelle 11.5), erfahren jedoch keine Besserung der ebenfalls vorhandenen akuten septischen Kardiomyopathie: der erniedrigte linksventrikuläre Schlagarbeitsindex zeigt keinen relevanten Anstieg. Dies deutet darauf hin, daß der Schädigung des Kreislaufs und des Herzens in der Sepsis unterschiedliche Schädigungsmechanismen zugrunde 
liegen, die sich unäbhangig voneinander bessern lassen bzw. unterschiedlich beeinflußt werden können.

\section{Extrakorporale Therapieverfahren: Hämofiltration und Plasmapherese}

Extrakorporale Therapieverfahren werden bei Sepsis und Multiorganversagen nicht nur zur Behandlung des akuten Nierenversagens eingesetzt, sondern auch in der Vorstellung, schädliche Bakterientoxine und Sepsismediatoren zu eliminieren (Zitate 41, 45, 46 in [55]). Im Tierexperiment lassen sich damit bei Sepsis sowohl eine Besserung der Kreislaufschädigung (Anstieg des systemischen Gefäßwiderstands) bei Schweinen (Zitat 60 in [14]) als auch eine Besserung der linksventrikulären Dysfunktion bei Hunden (Zitat 18 in [14]) nachweisen.

Zwar ist bei Patienten mit septischem Schock über eine Erholung der Herzfunktion durch Hämofiltration berichtet worden (Zitat 19 in [14]); es fehlen allerdings bisher noch kontrollierte Studien hinsichtlich des Einflusses einer Hämofiltration bzw. Plasmapherese auf die Herz-Kreislauf-Funktion.

Bei postoperativem Nierenversagen - nicht nur septischer Genese - korrelierte die Menge des täglichen Ultrafiltrates ( $>151 /$ Tag vs. $<151 /$ Tag) signifikant mit der Überlebensrate der Patienten; ob dies v.a. auf eine Besserung der HerzKreislauf-Schädigung zurückzuführen ist, läßt sich dabei nicht ersehen (s. Kap. 9). Durch Hämoperfusion mit einer Polymyxinsäule zur Endotoxinelimination ließ sich bei 42 Sepsispatienten die Endotoxinämie signifikant senken (von $85 \mathrm{pg} / \mathrm{ml}$ auf $28 \mathrm{pg} / \mathrm{ml}$ innerhalb eines Tages nach Therapiebeginn); die Behandlung besserte auch die Herz-Kreislauf-Funktion (Anstieg des systemischen Gefäßwiderstands und des Herzindex sowie des $\mathrm{O}_{2}$-Verbrauchs) dieser Patienten [16]. Eigene kasuistische Erfahrungen mit Plasmapherese belegen bei 4 von 10 Patienten mit septischem Schock einen relevanten Anstieg des systemischen Gefäßwiderstands innerhalb von 24-48 h nach Beginn der Plasmapheresebehandlung [14]; bezogen auf das Gesamtkollektiv von jetzt 11 Patienten findet sich jedoch keine eindeutig günstige Wirkung auf Kreislauf (systemischer Gefäßwiderstand) und Herzfunktion (Herzindex, linksventrikulärer Schlagarbeitsindex; Tabelle 11.5). Auch in engem zeitlichen Zusammenhang mit der Hämofiltration ließ sich bei 8 Patienten mit septischem Schock keine wesentliche Besserung der Herz- und Kreislauffunktion erkennen (Tabelle 11.5).

\section{Kortikoide}

In 3 großen kontrollierten Sepsisstudien konnte die hochdosierte Gabe von Glukokortikoiden die Letalität nicht senken (Zitate 81-83 in [27], S. 104-118). Bemerkenswert ist jedoch, daß in einer dieser Studien (Zitat 81) mit Patienten im refraktären septischen Schock die Schocksymptomatik bei 11 der 43 mit Glukokortikoiden behandelten Patienten innerhalb von $24 \mathrm{~h}$ beseitigt werden konnte, dagegen bei keinem der Patienten der Kontrollgruppe. 
Unter der Vorstellung, daß eine Subgruppe von Patienten im septischen Schock ein relatives Kortikoiddefizit entwickelt, wurden Patienten im septischen Schock mit hochphysiologischen Dosen von Hydrocortison (100-mg-Bolus, kontinuierliche Infusion von $10 \mathrm{mg} / \mathrm{h}$ ) therapiert ([27], S. 104-118). Bei insgesamt 20 der 30 behandelten Patienten konnte innerhalb von 48 h die Katecholamindosierung um mehr als $60 \%$ reduziert werden; diese „Responder“ - mit niedrigeren Cortisolspiegeln als „Non-Responder“ - hatten eine geringere Letalitat.

\section{Naloxon}

Die im septischen Schock erhöhten Plasmaendorphinspiegel (Zitat 9 in [41]) werden für die Hypotension mitverantwortlich gemacht. Eine vorübergehende Anhebung des Blutdrucks läßt sich gelegentlich durch die hochdosierte Gabe des Opiatantagonisten Naloxon erzielen ([37], S. 401-413; [41]). Bei fraglichem Therapieerfolg kann dieses Vorgehen wegen der z.T. schwerwiegenden Nebenwirkungen [41] derzeit nicht empfohlen werden.

\section{Zyklooxygenasehemmer}

Trotz vielversprechender tierexperimenteller Befunde (Diskussion in [27], S. 104-118) mit Zyklooxygenasehemmern wie Indomethacin und Ibuprofen konnten in einer kürzlich publizierten, allerdings methodisch kritisierten klinischen Studie keine vorteilhaften Wirkungen von Ibuprofen auf die Hämodynamik (Herzzeitvolumen, systemischer Gefäßwiderstand) bei schwerer Sepsis nachgewiesen werden [10].

\section{Pentoxifyllin}

Der Phosphodiesterasehemmer Pentoxifyllin hemmt über einen Anstieg des intrazellulären cAMP die Transkription von TNFmRNS in Makrophagen/Monozyten. Die in Sepsistiermodellen gefundenen günstigen Effekte auf die Schädigung von Herz/Kreilauf - Abschwächung des Blutdruckafalls und der Abnahme des Herzzeitvolumens (Diskussion in [24], S. 1587; [27], S. 104-118) - werden derzeit in klinischen Studien überprüft.

\section{Hemmung der Stickoxidproduktion}

Die therapierefraktäre Hypotension im Rahmen des septischen Schocks wird zumindest zum überwiegenden Teil auf eine endotoxin- und zytokininduzierte Überproduktion des vasodilatatorisch wirksamen Stickoxids (NO) in Endothelund Gefäßmuskelzellen zurückgeführt, ebenso wie das verminderte Ansprechen 
der Gefäße auf $\alpha$-Sympathomimetika (Abb. 11.7; [27], S. 94-103). Auch die negativ-inotropen Wirkungen von Zytokinen (Tumornekrosefaktor $\alpha$, Interleukin 1, Interleukin 2, Interleukin 6) werden teilweise durch Stimulation einer induzierbaren Stickoxidsynthase im Herzen vermittelt, mit Produktion von Stickoxid und konsekutiver Aktivierung der Guanylatzyklase (Abb. 11.7; [8, 21, 55]).

Patienten mit Sepsis haben erhöhte Plasmaspiegel der stabilen Abbauprodukte des Stickoxids. Hemmer der NO-Synthase - $\mathrm{N}^{\mathrm{G}}$-monomethyl-L-Arginin (LNMMA) oder NG-nitro-L-Arginin Methylester (NAME) - und der Guanylatzyklase - Methylenblau - können in der Sepsis zweifellos die Hypotonie durch eine Anhebung des erniedrigten Gefäßwiderstandes günstig beeinflussen. Im Hinblick auf die septische Kardiomyopathie sprechen die vorliegenden experimentellen und klinischen Befunde jedoch eher für eine Verschlechterung (Abfall des Herzindex und Schlagvolumenindex) als für die erhoffte Verbesserung der Herzfunktion durch diese Verbindungen, mit der weiteren Gefahr einer durch die Hemmung der Stickoxidproduktion ausgelösten Koronarkonstriktion und pulmonalen Hypertonie (ausführliche Diskussion und Literatur in [21, 55]).

Aufgrund der vorliegenden Befunde erscheint es fraglich, ob durch den Einsatz von Hemmern der Stickoxidsynthase und Guanylatzyklase eine günstige Wirkung auf die Herz-Kreislauf-Schädigung in der Sepsis ausgeübt werden kann ([21, 23]; [27], S. 94-103 und 104-118; [28, 55, 58]).

\section{Kausale Therapie der akuten septischen Kardiomyopathie: gegenwärtiger Stand}

Trotz der Aufklärung zahlreicher Toxin- und Zytokinwirkungen auf Herz und Kreislauf und der Entwicklung von Toxin- und Mediatorantikörpern müssen aufgrund der vorliegenden Studienergebnisse die kausalen Therapiemöglichkeiten derzeit noch als sehr limitiert eingestuft werden. Die septische Kreislaufschädigung mit Blutdruckabfall infolge der ausgeprägten Vasodilatation scheint dabei noch besser angehbar als die akute septische Kardiomyopathie (Abb. 11.10, Tabelle 11.5; [55]).

Es ist auch durchaus denkbar und durch experimentelle Befunde wahrscheinlich gemacht, daß der Schädigung von Herz und Kreislauf in der Sepsis nicht eine einzige gemeinsame Toxin-Mediator-Kaskade zugrunde liegt, sondern unterschiedliche (Diskussion in [55]). Je nach Sepsisstadium könnte weiterhin die Bedeutung der einzelnen Toxine und Mediatoren variieren. Die Folge davon wäre, daß auf eine bestimmte Toxin- und Mediator-neutralisierende bzw. -antagonisierende Therapieform nur jeweils ein Teil der Patienten überhaupt ansprechen könnte, und auch nur wiederum in einem bestimmten Zeitintervall. Eine bisher noch wenig praktizierte kausale Differentialtherapie von septischer Vaskulo- und Kardiomyopathie wäre die logische Antwort darauf [55]. Ihr Erfolg wäre aber nicht nur vom effizienten Medikament, sondern auch von der Identifizierung des „Responder Patienten“ (Text zu Abb. 6 in Referenz [2]; Abb. 2-5 in Referenz [3]; [29]) abhängig. 
Die akute septische Kardiomyopathie wird besonders augenscheinlich, wenn die Herzfunktionsparameter in Abhängigkeit vom systemischen Gefäßwiderstand beurteilt werden (Abb. 11.2). Die Ergebnisse einer kausalen Behandlung der Herzinsuffizienz in der Sepsis stehen derzeit noch hinter denen der symptomatischen Therapie mit Katecholaminen zurück (vgl. Tabellen 11.4, 11.5).

Bei kritischer Wertung der vorliegenden Untersuchungsergebnisse muß betont werden, daß viele der aufgeführten Daten aus jeweils einer einzelnen Studie stammen bzw. bisher nur von jeweils einer einzelnen Untersuchergruppe beschrieben worden sind und somit noch ihrer Bestätigung und Absicherung bedürfen.

\section{Spezielle Aspekte bei der Behandlung der rechtsventrikulären Dysfunktion bei akuter septischer Kardiomyopathie ([27], S. 89-93; [36, 52])}

Obwohl die Linksherzinsuffizienz klinisch mehr im Vordergrund steht, besitzt auch die Einschränkung der rechtsventrikulären Pumpfunktion eine große prognostische Bedeutung. Sie resultiert aus der dokumentierten systolischen und auch diastolischen (Linksverschiebung der Druck-Volumen-Kurven) Funktionsstörung. Neben einer dominanten Myokarddepression wird v. a. die pulmonale Hypertonie bei ARDS für das primär rechtskardiale Pumpversagen verantwortlich gemacht, während koronare Perfusionsstörungen eher die Ausnahme darstellen. Rechtsventrikuläre Dilatation und Abnahme der rechtsventrikulären Auswurffraktion sind der Messung mit einem speziellen Rechtsherzkatheter (s. Tabelle 11.5) zugänglich, sie führen sekundär zu einer Abnahme des linksventrikulären Füllungsdrucks und damit auch zur linksventrikulären Pumpfunktionseinschränkung. Die rechtsventrikuläre Dysfunktion kann sowohl isoliert als auch in Kombination mit einer Einschränkung der linksventrikulären Auswurffraktion vorkommen.

Auch bei der Behandlung der rechtsventrikulären Dysfunktion ist der erste Schritt die Volumensubstitution zum Ausgleich einer Hypovolämie, unter Messung der rechts- und linksventrikulären Füllungsdrücke und ggf. auch der rechtsventrikulären Volumina und der rectsventrikulären Auswurffraktion. Das Ausmaß der Volumensubstitution wird gerade bei im Vordergrund stehender rechtsventrikulärer Dysfunktion kontrovers diskutiert: Bei der Patientengruppe mit rechtsventrikulärer Dilatation und niedrigem Koronarperfusionsdruck läßt sich durch Volumensubstitution allein das Herzzeitvolumen nicht ausreichend steigern; bei diesen Patienten ist der frühzeitige Einsatz von vasokonstriktorischen Katecholaminen zur Anhebung des Koronarperfusionsdrucks erforderlich.

Zur Identifizierung dieser Zielgruppe mit rechtsventrikulärer Dysfunktion- in einer Untersuchung 40\% aller Patienten mit septischem Schock [36] - dient die auf $<45 \%$ reduzierte rechtsventrikuläre Auswurffraktion. Diese kann mittels eines modifizierten Swan Ganz Katheters (Thermodilution Ejection Fraction/ 
Volumetric Catheter 93A-443 H-7.5F, Baxter Health Care Corporation) gemessen werden. Bei Patienten mit einer rechtsventrikulären Auswurffraktion von weniger als $45 \%$ ließ sich durch alleinige Flüssigkeitssubstitution der Blutdruck nicht stabilisieren; positiv inotrope und/oder vasoaktive Pharmaka waren obligat, um einen ausreichenden Perfusionsdruck (arterieller Mitteldruck $>60 \mathrm{~mm} \mathrm{Hg}$ ) nach der Flüssigkeitsgabe zu erzielen und aufrechtzuerhalten [36].

Persistieren nach der Volumenkorrektur Hypotonie und Schock, so empfiehlt Dhainaut ([27] S. 89-93) als nächsten Schritt den differentialtherapeutischen Einsatz von Katecholaminen: bei normaler rechtsventrikulärer Auswurffraktion Dopamin, bei erniedrigter rechtsventrikulärer Auswurffraktion die Kombination von Dopamin und Dobutamin. Insgesamt ist jedoch die Diskussion um das „ideale“ Katecholaminregime bei primär rechtsventrikulärer septischer Herzschädigung noch in vollem Gange (Zitate 44 und 54 in [56]); die Möglichkeit zur detaillierten Quantifizierung des Therapieerfolgs wird im Einzelfall sicherlich hilfreich sein.

\section{Akute septische Kardiomyopathie und kardiale Vorerkrankungen}

Kardiale Vorerkrankungen können die Myokarddepression der akuten septischen Kardiomyopathie überlagern und aggravieren: Stenose-/Insuffizienz- oder Shuntvitium, dilatative oder hypertrophische Kardiomyopathie, dekompensiertes Hochdruckherz, Endo-/Myo-/Perikarditis im Rahmen der akuten infektiösen Erkrankung. Quantitativ die größte Rolle dürfte das Zusammentreffen einer septischen Herzschädigung mit einer koronaren Herzerkrankung spielen ([34]; [37], S. 104-123) - mit Überlagerung der septisch bedingten Myokarddepression durch die Myokardischämie im Rahmen der koronaren Herzkrankheit. Das bei Vasodilation gesteigerte Herzzeitvolumen erfordert einen höheren myokardialen $\mathrm{O}_{2}$-Verbrauch, der bei fixierten Koronarstenosen zur Verstärkung einer regionalen Myokardischämie führen kann. Eine laufende antianginöse Therapie mit $\beta$-Blockern, Nitraten und Kalziumantagonisten kann wiederum die labile HerzKreislauf-Situation des Septikers verschlechtern. Auf die erhöhte Volumenempfindlichkeit dieser „steifen Ventrikel“ wurde bereits hingewiesen, ebenso auf die Bevorzugung des Dobutamins gegenüber dem Dopamin (s. S. 221-222). Differentialdiagnostische Probleme mit differentialtherapeutischen Konsequenzen kann das Zusammentreffen von kardiogenem und septischem Schock bereiten, z. B das Auftreten einer Sepsis bei einem beatmeten Patienten mit kardiogenem Schock nach Myokardinfarkt. Invasive Parameter (Herzindex und systemischer Gefäßwiderstand) liefern zwar hier rasch eine Klärung über das dominierende Schockgeschehen; dagegen sind nichtinvasive Einzelparameter wie Fieber, Leukozytose und Blutlaktat wenig aussagekräftig [30]. Hier sind Scoresysteme zur Differenzierung hilfreich: so unterscheiden der APACHE-II- und der Sepsisscore nach Elebute u. Stoner mit ausreichender Sensitivität und Spezifität den kardiogenen vom septischen Schock: APACHE-II-Score: 20,3 \pm 8,4 (SD) (kardiogener Schock) vs. $29,3 \pm 6,6$ (septischer Schock); Sepsisscore: 11,0 \pm 5,8 vs. 19,0 \pm 5,9 [30]. 


\section{Therapie der Herzinsuffizienz bei primär abakteriellem Multiorganversagen}

Die Mehrzahl der Daten zur Pathophysiologie und Therapie der Herzinsuffizienz bei Sepsis und Multiorganversagen wurde bei Patienten mit bakterieller Sepsis und septischem Schock erhoben. Die gemeinsame Mediator-/Zytokinendstrecke macht es verständlich, daß die akute septische Kardiomyopathie sich bei gramnegativer und grampositiver Infektion sehr ähnilich darstellt; demzufolge sind die in diesem Artikel beschriebenen therapeutischen Maßnahmen auch nicht unterschiedlich. Sehr viel weniger bekannt ist über die Herz-Kreislauf-Schädigung bei septischen Virus- und Pilzerkrankungen; die symptomatische Therapie der Herzinsuffizienz bei diesen Formen unterscheidet sich derzeit nicht von der bei bakterieller Sepsis.

Bei den Patienten mit Multiorganversagen ohne zugrundeliegende Infektion repräsentieren Traumapatienten eine relevante Gruppe [4, 17]. Auch bei diesen Patienten mit SIRS kann eine hyperdyname Herz-Kreislauf-Reaktion nachgewiesen werden; die Myokardeinschränkung scheint jedoch geringer als bei vergleichbar hyperzirkulatorischen Sepsispatienten zu sein [35]; eine notwendige symptomatische Therapie der Herzinsuffizienz ist vergleichbar.

Bei SIRS-Patienten mit hypovolämischem Schock kommt es nach Blutungen, nach Verbrennungen mit Plasmaverlust oder bei ausgeprägter Vasodilatation (anaphylaktischer Schock) zu einem starken Abfall des effektiven intravasalen Blutvolumens und damit zur Vorlastabnahme und zur Absenkung des Herzzeitvolumens [49]. Neben der sicherlich dominanten Myokardhypoxie infolge des erniedrigten koronaren Perfusionsdrucks werden bei diesen Patienten auch noch weitere zur Myokarddepression führende, in ihrem Stellenwert aber noch zu bestimmende Mechanismen angenommen, wie z. B. eine Katecholamindesensibilisierung infolge erhöhter Plasmakatecholaminspiegel und das Auftreten myokarddepressiver Faktoren ([21]; [27], S. 62-77). Die symptomatische Therapie der Herzinsuffizienz dieser Patienten folgt ebenfalls den auf S. 209-233 gegebenen Vorschlägen.

\section{Empfehlungen der intensivmedizinischen Gesellschaften zur Therapie der septischen Herz-Kreislauf-Schädigung}

Eine 1994 in Brüssel abgehaltene, von den europäischen und amerikanischen Intensivmedizin-Gesellschaften unterstützte Konferenz [42] hat den derzeitigen gesicherten Kenntnisstand zur Sepsistherapie in Form graduierter Empfehlungen (A-C) zusammengefaßt (Grad A: am besten abgesichert; Grad C: am wenigsten abgesichert). Die für die Behandlung der Herz-Kreislauf-Schädigung relevanten Richtlinien sollen das Kapitel der Prophylaxe und Therapie der akuten septischen Kardiomyopathie abschließen. 


\section{1) Allgemeines Behandlungskonzept}

Bei Sepsistherapiemaßnahmen hat die definitive Versorgung des zur Sepsis führenden Infektionsherdes - Fokuseliminierung und antiinfektöse Maßnahmen - höchste Priorität. Die supportive Behandlung beinhaltet die Aufrechterhaltung einer ausreichenden Gewebeoxygenierung mit Flüssigkeitssubstitution und die Gabe vasoaktiver Pharmaka. Eine adäquate Ernährung wird als wichtige Komponente des Gesamttherapiekonzepts angesehen. Schließlich finden Strategien zur Modifikation exzessiver Mediatorbildung in der Sepsis zunehmende Beachtung.

\section{2) Flüssigkeitstherapie}

Sepsispatenten sind durch ein absolutes und relatives intravasales Volumendefizit charakterisiert. Die sofortige und adäquate Flüssigkeitstherapie ist der entscheidende erste Schritt zur Behandlung des septischen Schocks. Als akzeptable Zielkriterien können die kardialen Füllungsdrucke dienen. Der Pulmonalkapillardruck sollte einen Wert von 16-18 mm Hg nicht überschreiten; er sollte gerade so niedrig gehalten werden, daß ein Blutdruck, der eine adäquate zentrale und periphere Durchblutung gewährleistet, noch aufrechterhalten werden kann (Grad C). Es gibt keine eindeutige Evidenz dafür, daß kolloidale Lösungen bei der Flüssigkeitstherapie septischer Patienten den kristalloiden Lösungen überlegen sind; allerdings sollten ausgeprägte Abfälle des kolloidosmotischen Drucks vermieden werden (Grad B). Plasmaersatzlösungen sind im Vergleich zu Albumin äquieffektiv, und sie sollten auf grund der niedrigeren Kosten bevorzugt werden (Grad C). Einige dieser Lösungen haben jedoch (geringe) Wirkungen auf die Hämostase, die bei manchen Patienten unerwünscht sein können. Das individuelle Vorgehen bei jedem einzelnen Patienten wird besonders hervorgehoben.

\section{3) Erythozytentransfusion}

Die Hämoglobinspiegel sollten bei Patienten mit Sepsis auf Werte über $100 \mathrm{~g} / \mathrm{l}$ gehalten werden ( Grad B/C+).

\section{4) Therapie mit vasoaktiven Pharmaka}

Die Behandlung mit vasoaktiven Pharmaka sollte den septischen Patienten vorbehalten werden, bei denen mit alleiniger Volumensubstitution kein ausreichender Perfusionsdruck erzielt werden kann, um eine adäquate Nieren- und Hirndurchblutung zu gewährleisten. Bei den Sympathomimetika sind inotrop wirksame den reinen Vasopressoren vorzuziehen; Adrenalin ist dabei kein bevorzugtes Pharmakon (Grad B). Phosphodiesterasehemmer werden nicht als Pharmaka der ersten Wahl zur Behandlung der hämodynamischen Instabilität empfohlen; und es gibt 
auch keine überzeugenden Befunde, um den Routineeinsatz von niedrig-dosiertem Dopamin (Nierendosis) zu empfehlen (Grad B).

\section{5) Systemisches Sauerstoffangebot}

Bei Fehlen einer Gewebesauerstoffschuld scheint ein supranormales systemisches $\mathrm{O}_{2}$-Angebot die Überlebenswahrscheinlichkeit nicht zu verbessern (Grad B), auch dann nicht, wenn es mittels „ $\mathrm{O}_{2}$-Transport-Indizes-Titration“ gesteuert ist (Grad A-B).

Dagegen wird den $\mathrm{O}_{2}$-Indizes, einschließlich der Messung von Laktat und des Magenintramukosa-pH - eine prognostische Bedeutung bei der Sepsis zugeschrieben (Grad A-B).

6)

Derzeit nicht zu empfehlen ist der Einsatz von Antiendotoxintherapien (Grad A), von Steroiden und Prostaglandin $E_{1}$ (Grad A), von Anti-TNF $\alpha$-Antikörpern, Interleukin-1-Rezeptorantagonisten, PAF-Antagonisten, N-Azetylzystein und Antioxidanzien.

\section{Literatur}

1. Boekstegers P, Weidenhöfer S, Werdan K (1991) Continuous measurement of peripheral tissue oxygenation in patients with sepsis: effect of systemic Pseudomonasimmunoglobulin treatment on mean skeletal muscle. Circ Shock 34 [Abstracts]: 75

2. Boekstegers P, Weidenhöfer S, Zell R, Pilz G, Holler E, Ertel W, Kapsner T, Redl H, Schlag G, Kaul M, Kempeni J, Stenzel R, Werdan K (1994) Repeated administration of a $\mathrm{F}\left(\mathrm{ab}^{\prime}\right)_{2}$ fragment of an anti-tumor necrosis factor $\alpha$ monoclonal antibody in patients with severe sepsis: effects on the cardiovascular system and cytokine levels. Shock 1: 237-245

3. Boekstegers P, Weidenhöfer S, Zell R, Holler E, Kapsner T, Redl H, Schlag G, Kaul M, Kempeni J, Werdan $\mathrm{K}$ (1994) Changes in skeletal muscle $\mathrm{pO}_{2}$ after administration of anti-TNF $\alpha$-antibody in patients with severe sepsis: comparison to interleukin-6 serum levels, APACHE II, and Elebute scores. Shock 1: 246-253

4. Conrad SA, Finkelstein JL, Madden MR, Burk J, Goodwin CW (1990) Cardiovascular dysfunction in multiple organ failure. In: Deitch EA (ed) Multiple organ failurepathophysiology and basic concepts of therapy. Thieme, New York, pp 172-191

5. Daniel WG, Mügge A (1995) Transesophageal echocardiography. N Engl J Med 332: 1268-1279

6. De Meules JE, Pigula FA, Mueller M, Raymond SJ, Gamelli RL (1992) Tumor necrosis factor and cardiac function. J Trauma 32: 686-692

7. Erdmann E, Reuschel-Janetschek E (1989) Hämodynamik in der Sepsis und im Septischen Schock. Intensivmedizin 26 [Suppl 1]: 16-21 
8. Finkel MS, Oddis CV, Jacob TD, Watkins SC, Hattler BG, Simmons RL (1992) Negative inotropic effects of cytokines on the heart mediated by nitric oxide. Science 257: 387-389

9. Gorscan J (1995) Quantification of left ventricular function using transesophageal echocardiography. In: Vincent J-L (ed) Yearbook of intensive care and emergency medicine 1995. Springer, Berlin Heidelberg New York Tokyo, pp 575-592

10. Haupt MT, Jastremski MS, Clemmer TP, Metz CA, Goris GB, the Ibuprofen Study Group (1991) Effect of ibuprofen in patients with severe sepsis; a randomized, doubleblind, multicenter study. Crit Care Med 19: 1339-1347

11. Hayes MA, Timmins AC, Yau EHS, Palazzo M, Hinds CJ, Watson D (1994) Elevation of systemic oxygen delivery in the treatment of critically ill patients. N Engl J Med 330: $1717-1722$

12. Jardin F, Brun-Ney D, Auvert B, Beauchet A, Bourdaris JP (1990) Sepsis-related cardiogenic shock. Crit Care Med 18: 1055-1060

13. Jardin F, Valtier B, Beauchet A, Dubourg O, Bourdarias JP (1994) Invasive monitoring combined with two-dimensional echocardiographic study in septic shock. Intensive Care Med 20: 550-554

14. Kääb S, Pilz G, Appel R, Samtleben W, Gurland HJ, Werdan K (1992) Extrakorporale Therapieverfahren: Möglichkeiten und klinische Relevanz bei Patienten mit septischem Multiorganversagen. In: Deutsch E, Kleinberger G, Lenz K, Ritz R, Schneeweiß B, Schuster HP, Simbruner G, Slany J (Hrsg) Multiorganversagen. Springer, Wien New York (Intensivmedizinisches Seminar, Bd 4, S 139-153)

15. Karzai W, Reilly JM, Hoffman WD, Cunnion RE, Danner RL, Banks SM, Parrillo JE, Natanson C (1995) Hemodynamic effects of dopamine, norepinephrine, and fluids in a dog model of sepsis. Am J Physiol 268: H692-H702

16. Kodama M, Aoki H, Tani T, Hanasawa K (1992) Hemoperfusion using polymyxin B immobilized fiber column for removal of endotoxin. Abstract-Band: Second Conference of the International Endotoxin Society, Wien, 17-20. August 1992, Abstr 38, S 38

17. Law WR (1992) Myocardial depression. In: Gamelli RL, Dries DJ (eds) Trauma 2000 Strategies for the New Millenium. Landes, Austin, pp 30-35

18. Löllgen H, Meuret GH (1989) Empfehlungen zur Therapie mit Katecholaminen in der Notfallmedizin. In: Vogel F (Hrsg) Differentialtherapie mit Katecholaminen-Pathophysiologische und klinische Aspekte. Thieme, Stuttgart (Intensivmedizin Notfallmedizin Anästhesiologie, Bd 70, S 11-13)

19. Lucas CE (1976) The renal response to acute injury and sepsis. Surg Clin North Am 56: 953-975

20. Manthous CA, Hall JB, Olson D, Singh M, Chatla W, Pohlman A, Kushner R, Schmidt GA, Wood LDH (1995) Effect of cooling on oxygen consumption in febrile critically ill patients. Am J Respir Crit Care Med 151: 10-14

21. Müller-Werdan U, Reithmann C, Werdan K (im Druck) Cytokines and the heart molecular mechanisms of septic cardiomyopathy. Landes, Austin, USA

22. Myles PS, Buckland MR, Schenk NJ, Cannon GB, Langley M, Davis BB, Weeks AM (1993) Effect of „renal-dose“ dopamine on renal function following cardiac surgery. Anaesth Intensive Care 21: 56-61

22a. Natanson C, Hoffman WD, Parrillo JE (1995) Septic shock and multiple organ failure. In: Parrillo JE, Bone RC (eds) Critical care medicine - principles of diagnosis and management. Mosby, St. Louis, pp 355-374

23. Nava E, Palmer RMJ, Moncada S (1991) Inhibition of nitric oxide synthesis in septic shock: how much is beneficial? Lancet 338: 1555-1557 
24. Niemer M, Nemes C, Lundsgaard-Hansen P, Blauhut B (1992) Datenbuch Intensivmedizin. Fischer, Stuttgart Jena New York (Datenbuch Anästhesiologie und Intensivmedizin, Bd 2)

25. Packman MI, Rackow EC (1983) Optimum left heart filling pressure during fluid resuscitation of patients with hypovolemic and septic shock. Crit Care Med 11: 165-169

26. Parrillo JE (1989) Septic shock in humans: clinical evaluation, pathogenesis, and therapeutic approach. In: Shoemaker WC, Ayres S, Grenvik A, Holbrook PR, Thompson WL (eds) Textbook of critical care, 2nd edn. Saunders, Philadelphia, pp 1006-1024

27. Peter K, Lawin P, Bein T (Hrsg) (1992) Intensivmedizin 1992. Thieme, Stuttgart New York (Intensivmedizin Notfallmedizin Anästhesiologie, Bd 81)

28. Petros A, Bennett D, Vallance P (1991) Effect of nitric oxide synthase inhibitors on hypotension in patients with septic shock. Lancet 338: 1557-1558

29. Pilz G, Werdan K (1990) Cardiovascular parameters and scoring systems in the evaluation of response to therapy in sepsis and septic shock. Infection 18: 253-262

30. Pilz G, Stäblein A, Reuschel-Janetschek E, Autenrieth G, Werdan K (1989) The use of scoring systems in patients with cardiogenic and septic shock. In: Schlag G, Redl H (eds) Second Vienna Shock Forum. Liss, New York (Progress in clinical and biological research, vol 308, pp 625-631)

31. Pilz G, McGinn P, Boekstegers P, Kääb S, Weidenhöfer S, Werdan K (1994) Pseudomonas sepsis does not cause more severe cardiovascular dysfunction in patients than nonPseudomonas sepsis. Circul Shock 42: 174-182

32. Quezado ZMN, Natanson C, Alling DW, Banks SM, Koev CA, Elin RJ, Hosseini JM, Bacher JD, Danner RL, Hoffman WD (1993) A controlled trial of HA-1A in a canine model of gram-negative septic shock. JAMA 269: 2221-2227

33. Rackow EC, Kaufman BS, Falk JL, Astiz ME, Weil MH (1987) Hemodynamic response to fluid repletion in patients with septic shock: evidence for early depression of cardiac performance. Circ Shock 22: 11-22

34. Raper RF, Sibbald WJ (1988) The effects of coronary artery disease on cardiac function in nonhypotensive sepsis. Chest 94: 507

35. Raper R, Sibbald WJ, Driedger AA, Gerow K (1989) Relative myocardial depression in normotensive sepsis. J Crit Care 4: 9-18

36. Redl G, Germann P, Plattner H, Hammerle A (1993) Right ventricular function in early septic shock states. Intensive Care Med 19: 3-7

37. Reinhart K, Eyrich K (Hrsg) (1989) Sepsis. Springer, Berlin Heidelberg New York Tokyo

38. Reinhart K, Bloos F, Spies C (1995) Vasoactive drug therapy in sepsis. In: Sibbald WJ, Vincent J-L (eds) Clinical trials for the treatment of sepsis. Springer, Berlin Heidelberg New York Tokyo, pp 207-224 (Update in Intensive Care and Emergency Medicine 19)

39. Reithmann C, Hallström S, Pilz G, Kapsner T, Schlag G, Werdan K (1993) Desensitization of rat cardiomyocyte adenylyl cyclase stimulation by plasma of noradrenalinetreated patients with septic shock. Circ Shock 41: 48-59

40. Reithmann C, Werdan K (1995) Klinische Ergebnisse der einzelnen therapeutischen Prinzipien: Katecholamine. In: Griebenow R, Gülker H, Dominiak P, Piper HM (Hrsg) Autonomes Nervensystem und Herzinsuffizienz. Thieme, Stuttgart New York, S 214-229

41. Rock P, Silverman H, Plump D, Kecala Z, Smith P, Michael JR, Summer W (1985) Efficacy and safety of naloxone in septic shock. Crit Care Med 13: 28-33

42. Sibbald WJ, Vincent J-L (1995) Roundtable conference on clinical trials for the treatment of sepsis. Chest 107: 522-527 
43. Sibbald WJ, Doig GS, Morisaki H (1995) Role of RBC transfusion therapy in sepsis. In: Sibbald WJ, Vincent J-L (eds) Clinical trials for the treatment of sepsis. Springer, Berlin Heidelberg New York Tokyo, pp 191-206

44. Silverman HJ, Penaranda R, Orens JB, Lee NH (1993) Impaired $\beta$-adrenergic receptor stimulation of cyclic adenosine monophosphate in human septic shock: association with myocardial hyporesponsiveness to catecholamines. Crit Care Med 21: 31-39

45. Sirtl C, Laubenthal H (1995) Therapie der Hypovolämie, Volumenersatztherapie. In: Madler C, Jauch K-W, Werdan K (Hrsg) Das NAW Buch - praktische Notfallmedizin. Urban \& Schwarzenberg, München Wien Baltimore, S 176-184

46. Thijs LG (1985) Fluid therapy in septic shock. In: Sibbald WJ, Vincent J-L (eds) Clinical trials for the treatment of sepsis. Springer, Berlin Heidelberg New York Tokyo, pp 167-190 (Update in intensive care and emergency medicine 19).

47. Thomas VL, Nielsen MS (1991) Administration of angiotensin II in refractory septic shock. Crit Care Med 19: 1084-1086

48. Thompson BT, Cockrill BA (1994) Renal-dose dopamine: a Siren song? Lancet 344: 7-8

49. Traber DL, Meyer J, Traber LD (1993) Cardiac function during hypovolemia. In: Schlag G, Redl H (eds) Pathophysiology of shock, sepsis, and organ failure. Springer, Berlin Heidelberg New York Tokyo, pp 194-199

50. Van der Meer NJM, Vries PMJ de (1995) Impedance cardiography: non-invasive monitoring of hemodynamics in the ICU. In: Vincent J-L (ed) Yearbook of intensive care and emergency medicine 1995. Springer, Berlin Heidelberg New York Tokyo, pp 615-628

51. Vincent JL, Thijs LG (eds) (1987) Septic shock - European view. Update in intensive care and emergency medicine 4. Springer, Berlin Heidelberg New York Tokyo

52. Vincent JL, Reuse C, Frank N, Contempre B, Kahn RJ (1989) Right ventricular dysfunction in septic shock: assessment by measurements of right ventricualr ejection fraction using the thermodilution technique. Acta Anaesthesiol Scand 33: 34-38

53. Vincent J-L, Bakker J, Marecaux G, Schandene L, Kahn RJ, Dupont E (1992) Administration of anti-TNF antibody improves left ventricular function in septic shock patients. Results of a pilot study. Chest 101: 810-815

54. Vincent J-L, Gris P, Coffernils M, Leon M, Pinsky M, Reuse C, Kahn RJ (1992) Myocardial depression characterizes the fatal course of septic shock. Surgery 111: 660-667

55. Werdan K (1995) Towards a more causal treatment of septic cardiomyopathy. In: Vincent J-L (ed) Yearbook of intensive care and emergency medicine 1995. Springer, Berlin Heidelberg New York Tokyo, pp 518-538

56. Werdan K, Reithmann C (1992) Differentialtherapie mit Katecholaminen. In: Schüttler J, Schwilden H, Lauven PM (Hrsg) Klinische Pharmakologie und rationale Arzneimitteltherapie. Thieme, Stuttgart New York (Intensivmedizin Notfallmedizin Anästhesiologie Bd 80, S 133-143)

57. Werdan K, Boekstegers P, Müller U, Pfeifer A, Pilz G, Reithmann C, Hallström S, Koidl B, Schuster HP, Schlag G (1991) Akute septische Kardiomyopathie: Bestandteil des Multiorganversagens in der Sepsis? Med Klin 86: 526-534

58. Wright CE, Rees DD, Moncada S (1992) Protective and pathological roles of nitric oxide in endotoxin shock. Cardiovasc Res 26: 48-57 